This article has been scanned by iThenticat No plagiarism detected

Volume 3, Issue 3, June 2021

p. 43-57

BARRIERS TO THE INTEGRATION OF ONLINE LEARNING AMONG ARAB

KINDERGARTEN TEACHERS IN PALESTINIAN COMMUNITY IN ISRAEL DURING COVID-19 PANDEMIC

http://dx.doi.org/10.47832/2757-5403.3-3.5

Hamzy EGBARIA 1

\begin{abstract}
:
This study aimed to shed lights on the obstacles to the application of online learning during COVID-19 pandemic in the Palestinian kindergartens in Israel and to determine the effect of the scientific qualification, the type of kindergarten, the practical experience, and training in using computer applications during academic studies. The researcher used the descriptive method. The study sample consisted of (3138) kindergarten teachers chosen randomly. The researcher developed a 17-item electronic questionnaire. The appropriate statistical analyses were used. The results showed that the degree of obstacles to the application of online learning ranged from low to moderate. Furthermore, there were significant statistical differences at the obstacles to the application of online learning related to practical experience and, and training in using computer applications during academic studies. In the light of these study results, a number of recommendations were made.
\end{abstract}

Key words: Barriers, Online learning, Kindergarten Teachers, Palestinian Community in Israel.

\footnotetext{
${ }^{1}$ Dr. , Atid Alahliya High School, hamzy@elahlya.net, https://orcid.org/0000-0001-7779-5313
} 


\title{
BARRIERS TO THE INTEGRATION OF ONLINE LEARNING AMONG ARAB \\ KINDERGARTEN TEACHERS IN PALESTINIAN COMMUNITY IN ISRAEL \\ DURING COVID-19 PANDEMIC
}

\section{معيقات تطبيق التعليم عن بعد عبر الإنترنت (تعليم الأونلاين) في ظل جائحة كورونا عند مربيات رياض الأطفال العربيات في الداخل الأنل القلنيطيني فئن}

\author{
2 حزة علي اغبارية
}

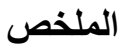

هدفت هذه الدراسة إلى الكثثف عن معوقات تطبيق التعليم عن بعد عبر الإنترنت (تعليم

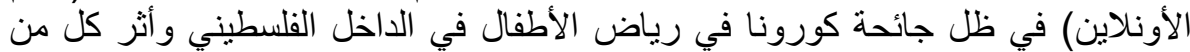

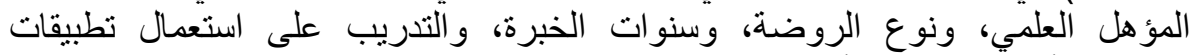

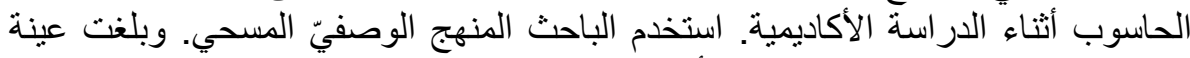

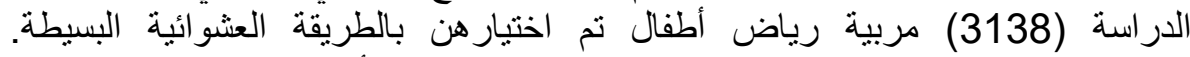

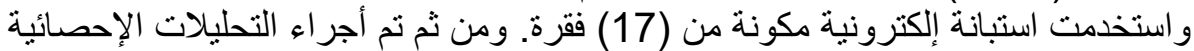

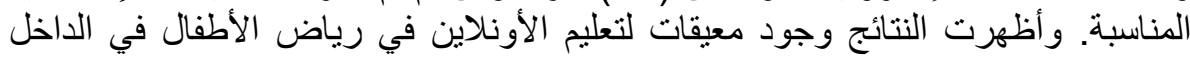

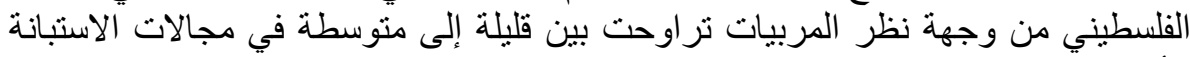

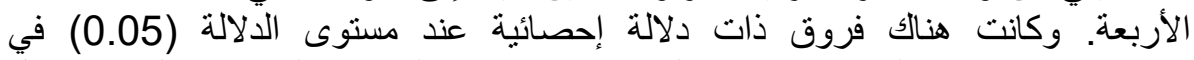

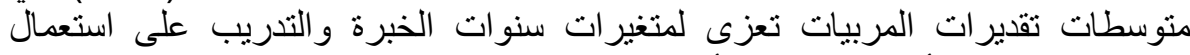
تطبيقات الحاسوب أثناء الدراسة الأكاديمية فقط. وعلى وعلى ضوء بعض التوصيات. الكلمات المفتاحية: معيقات، تعليم الأونلاين، مربيات رياض الأطفال، الداخل الفلسطيني.
\end{abstract}

كان لنشوب جائحة كورونا في أنحاء المعمورة في العامين المنصرمين الأثر الكبير على تعطيل مجالات الحياة المتعددة،

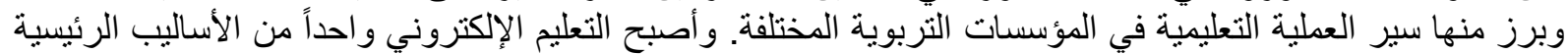

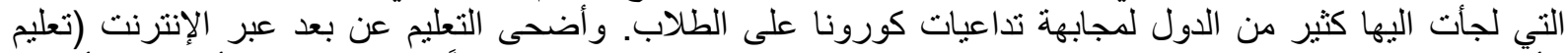

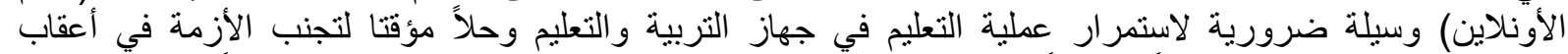

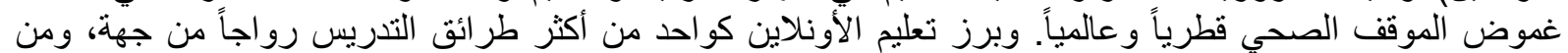

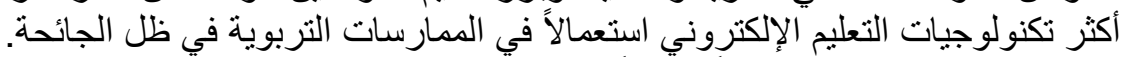

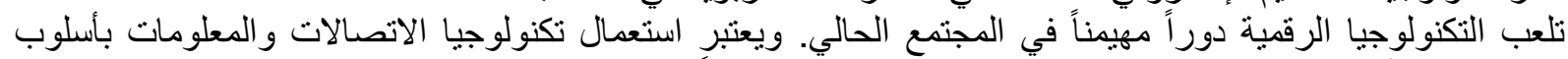

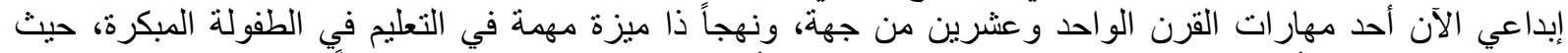

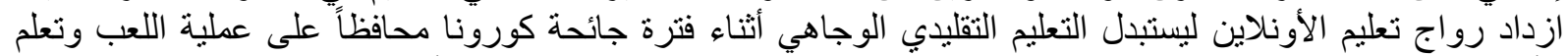

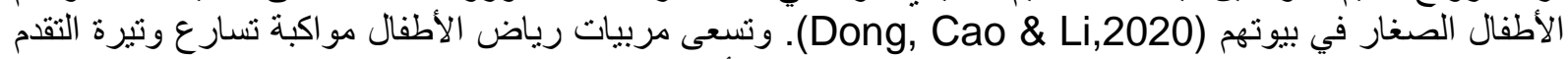

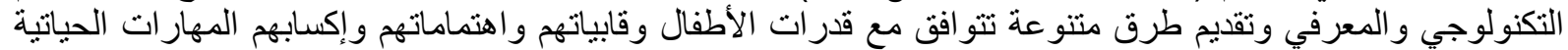

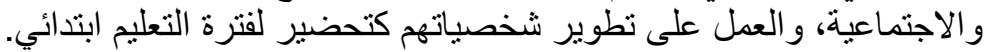

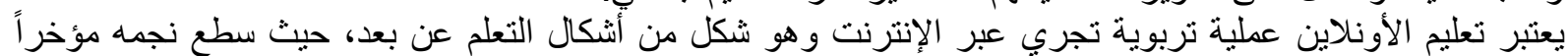

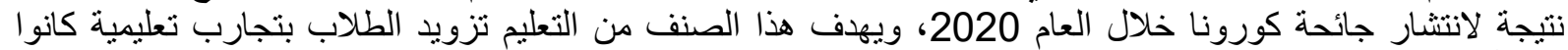

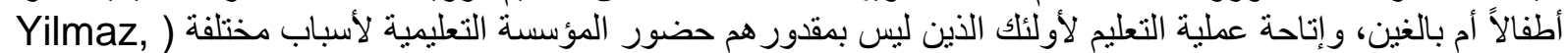

ويرى (Kim,2020) أن تدريس الأونلاين ينطلب انجاز العديد من المهام في مر احل التخطيط و التنفيذ و الاستبطان. كما

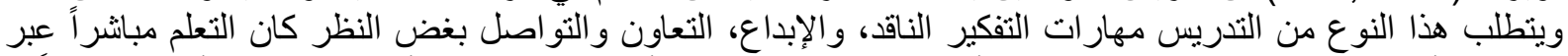

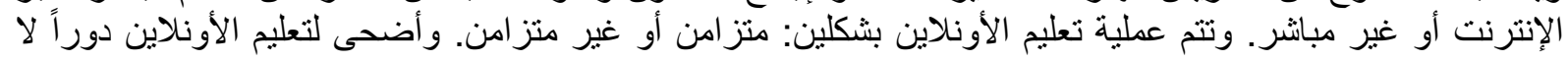


مفر منه في برامج التربية للطفولة المبكرة على الرغم من الجدل المستمر حول فائدة كثف الأطفال على نحو واسع لتكنولوجيا المعلومات و الاتصالات.

\section{تحديات تطبيق عملية تعليم الأونلاين}

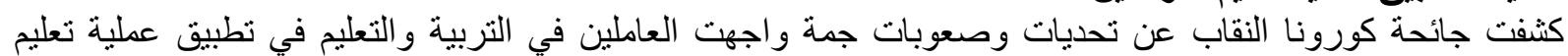
الأونلاين، ومن أبرز هذه التحديات الفيات

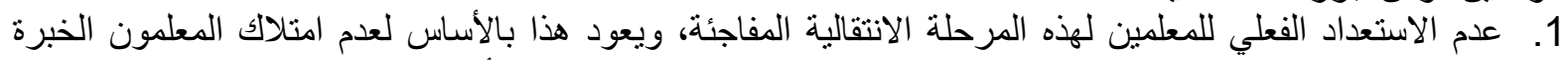

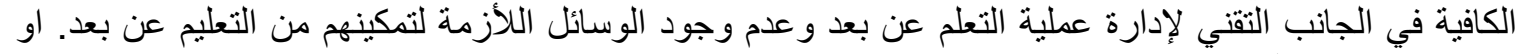
صناعة محتوى تعليمي ملائم.

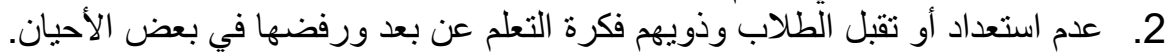

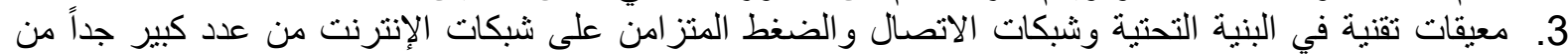
المستعملين في ان واحد. (مركز الملك سلمان للإِغاثة و الاعمال الإنسانية، الإنة 2020، 19-20)

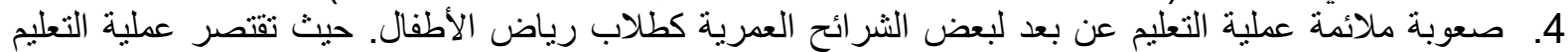

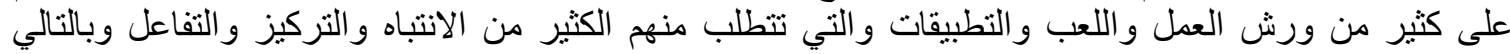
متابعة كبيرة من طرف من المربية.

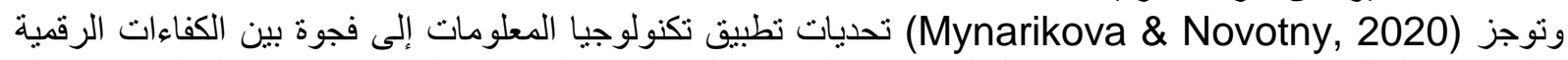

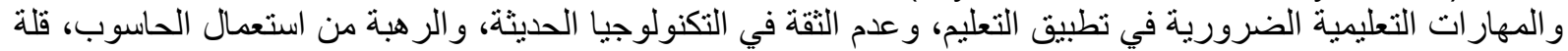

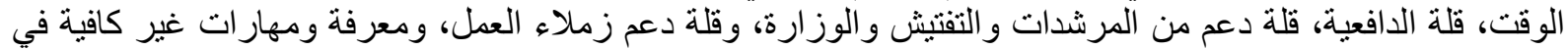

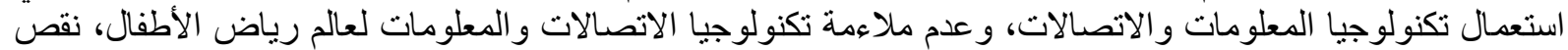

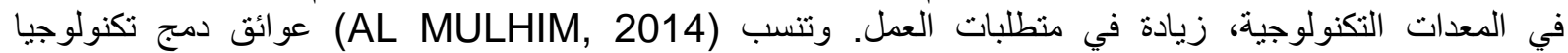

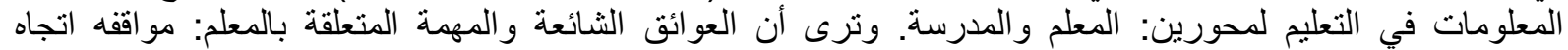

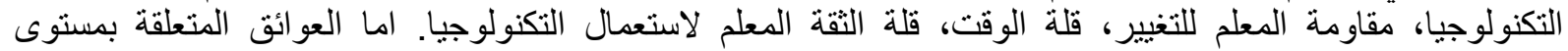

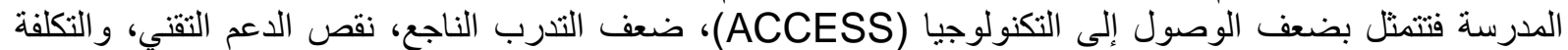

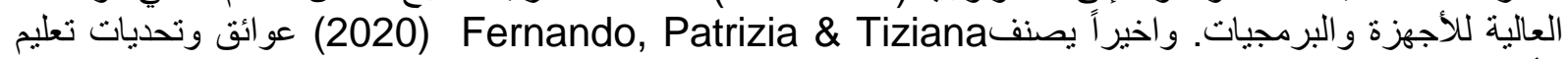
الأونلاين إلى ثلاث فئات:

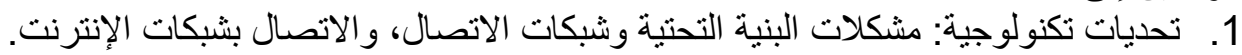

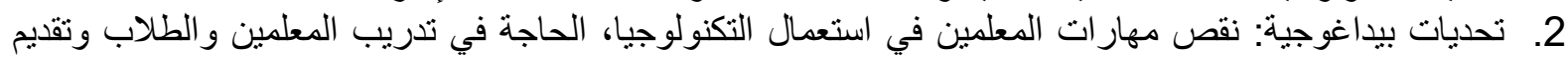

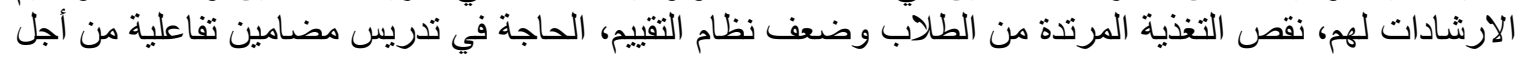

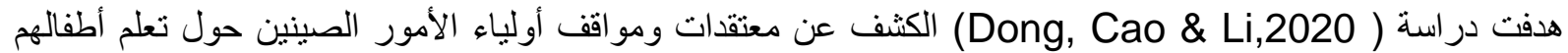

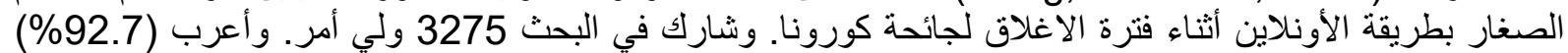

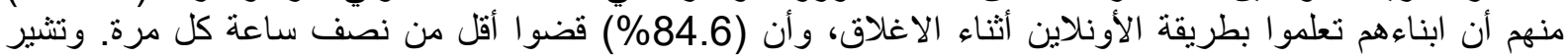

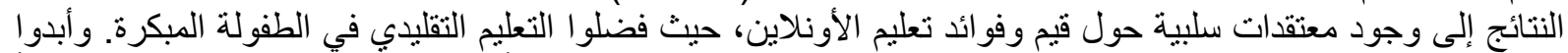

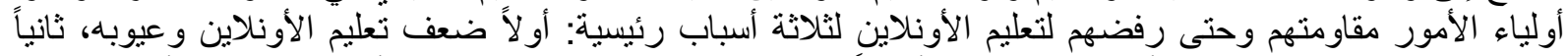

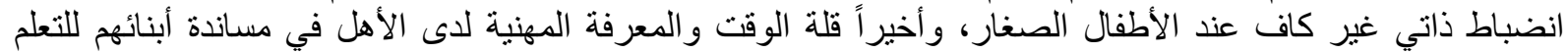

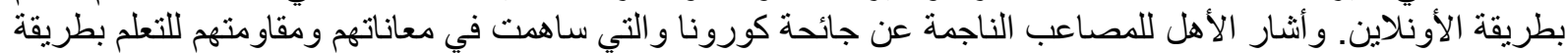

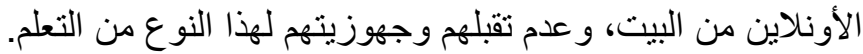
اما دراسة Noor, Isa \& Mazhar (2020) فنطرقت إلى ممارسات التدريس عبر الإنترنت أثناء جائحة كورونا في

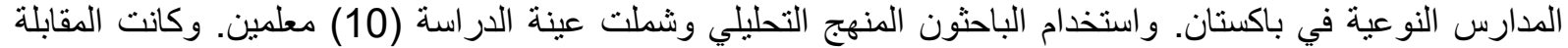

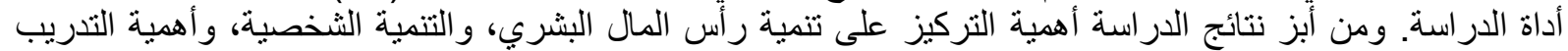

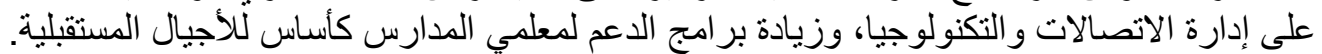

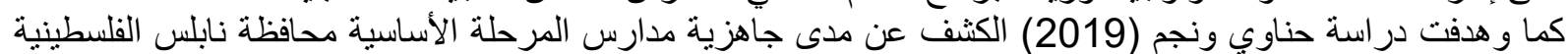

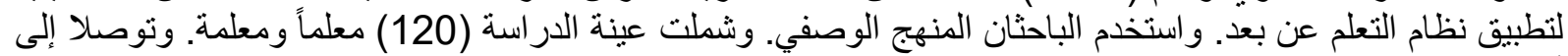

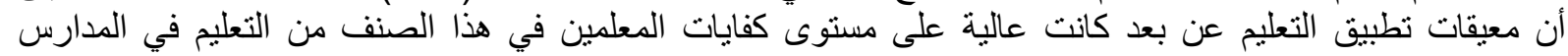
الابتدائية. 


\section{BARRIERS TO THE INTEGRATION OF ONLINE LEARNING AMONG ARAB KINDERGARTEN TEACHERS IN PALESTINIAN COMMUNITY IN ISRAEL DURING COVID-19 PANDEMIC}

هدفت دراسة (Kamarulzaman, Che, Mohd \& Mohd, 2017) فحص مستوى دمج تكنولوجيا الاتصالات

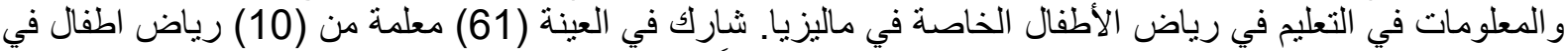

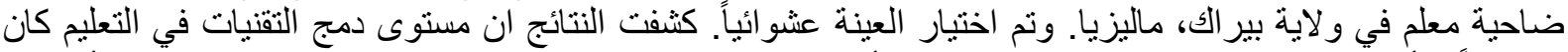

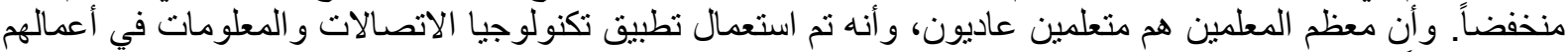

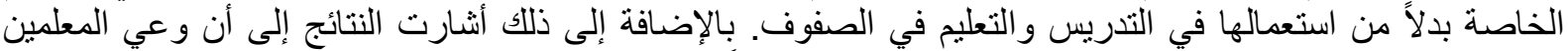

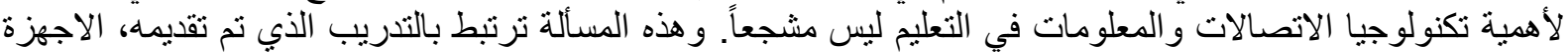

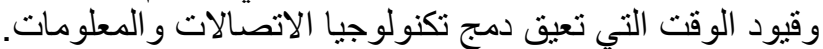
و هدفت در اسة (Fox, Diezmann,\& Lamb,2016) التطرق إلى معيقات تطبيق تكنولوجيا الاتوليات الاتلات و المعلومات

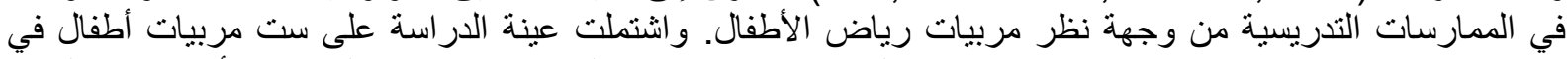

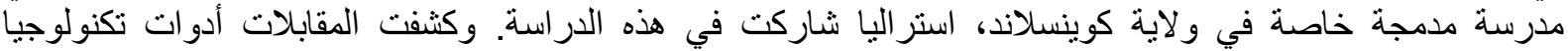

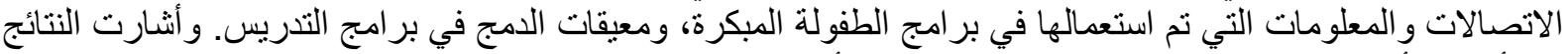

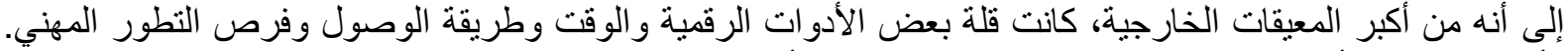

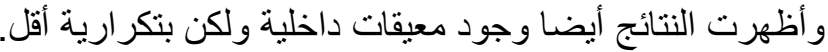
و هدفت دراسة (Liu \& Pange, 2015) إلى الكثف عن الأن المعيقات التي تواجه مربيات رياض الأطفال في دمج

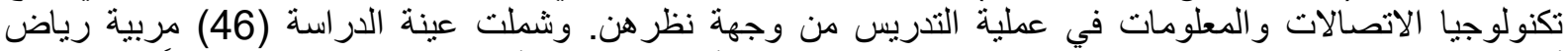

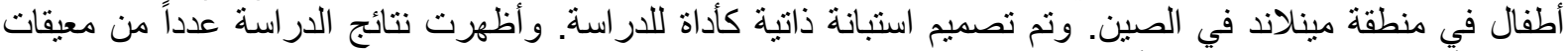

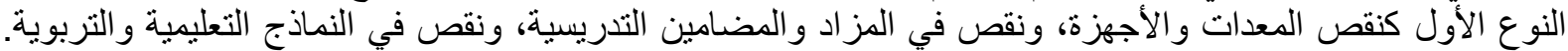

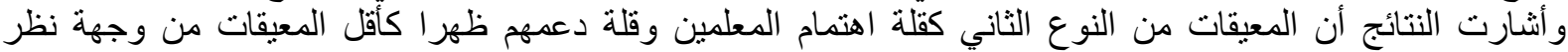

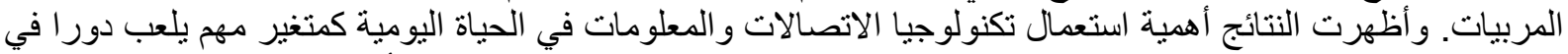

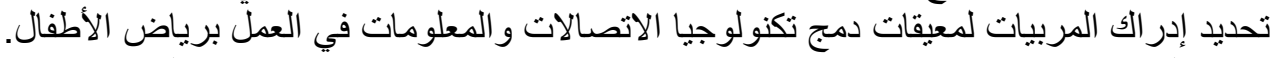

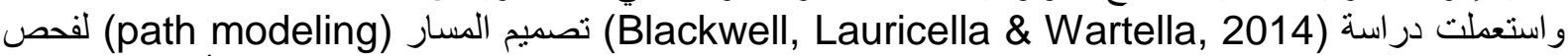

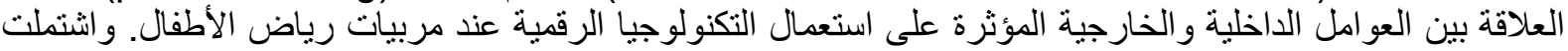

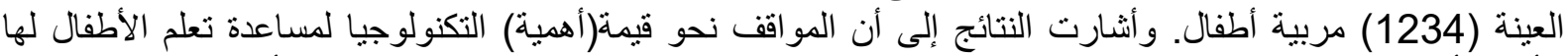

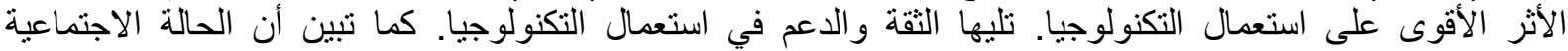

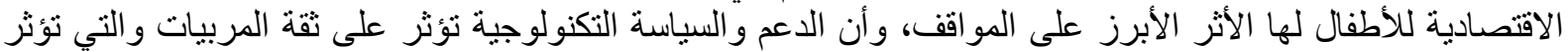

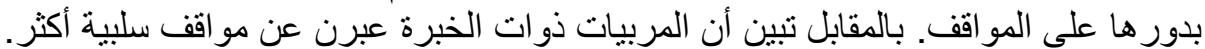

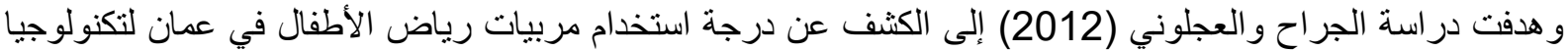

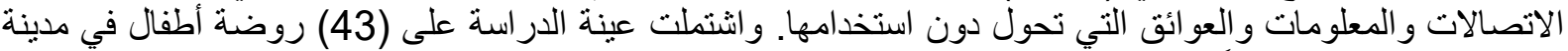

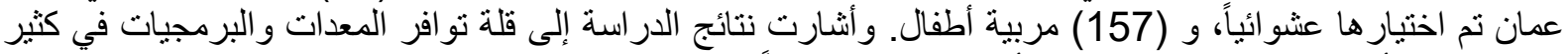

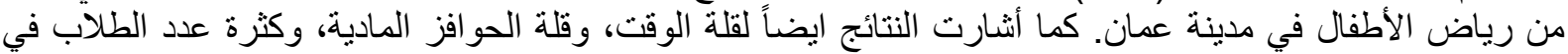

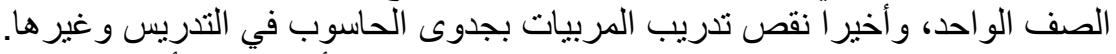

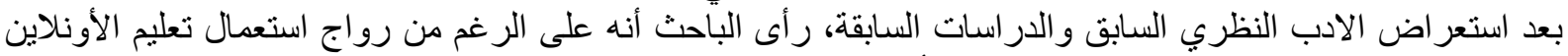

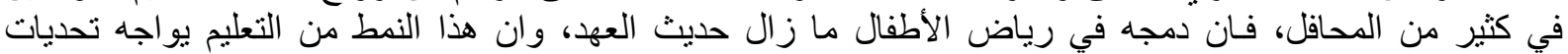
ومعيقات كثيرة تقف حجر عثرة في طريق نجاحه وناجعته في رياض الأطفال. زد على ذلى ذلك قلة الدراسات العربية و المحلية التي تنتاولت هذه المشكلة.

\section{مشكلة الاراسة وأسئلتها}

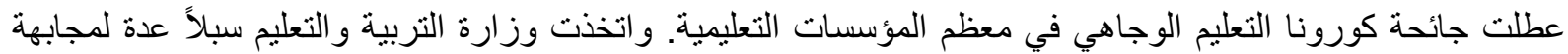

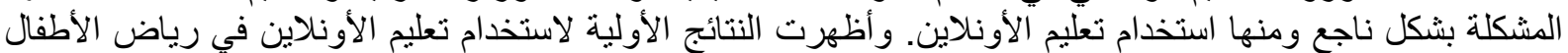

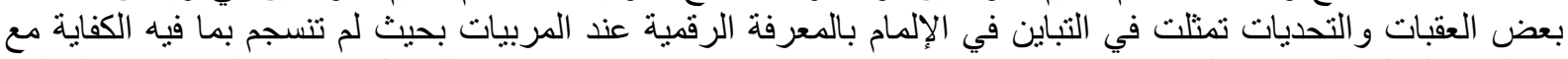

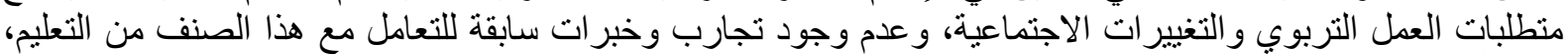

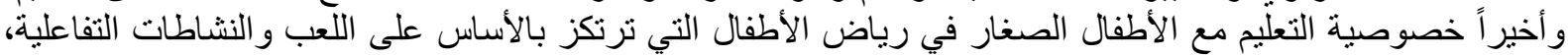

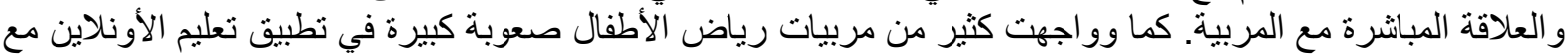

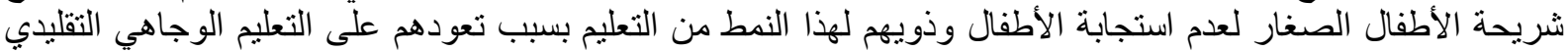

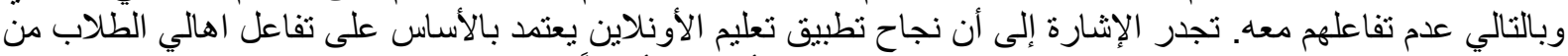

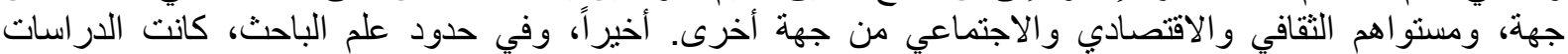


و البحوث العربية و المحلية التي تناولت هذه المشكلة شحيحة، ولم تجر أي دراسة حول معيقات وتحديات تعليم الأونلاين

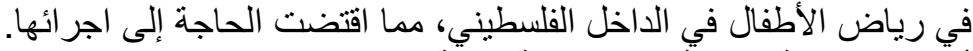
أجابت الاراسة الحالية عن الاسئلة الاتئة:

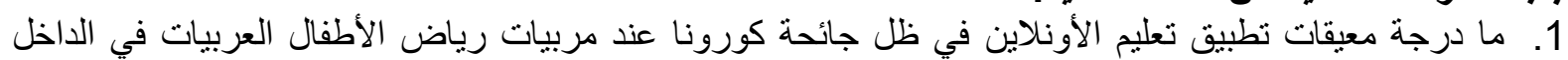

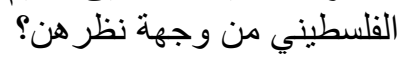

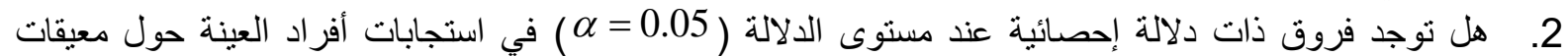

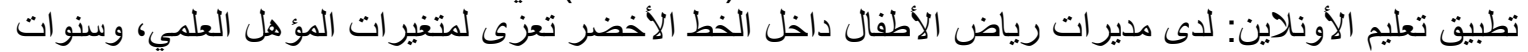

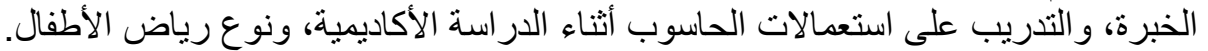

أهمية الاراسة

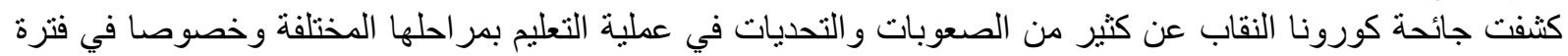

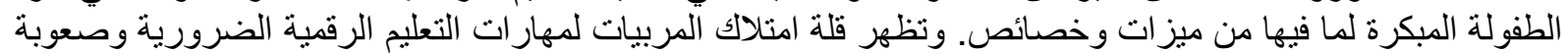

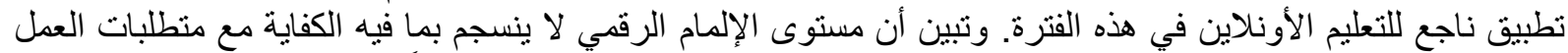

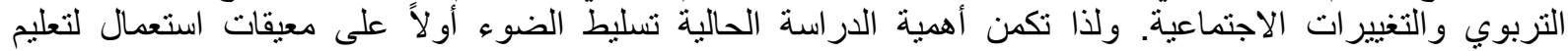

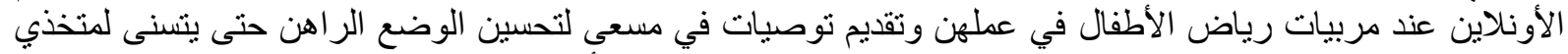

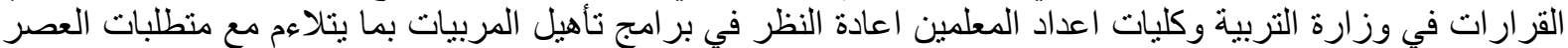
ومواكبة التطور ات المتسار عة غير المحدودة.

أهداف الاراسة تهدف الدراسة الحالية إلى فحص التحديات والعو امل المعيقة لتطبيق تعليم الأونلاين في ظل جائحة كورونا عند مربيات التيرة

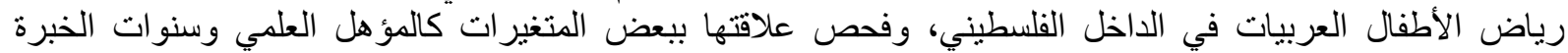

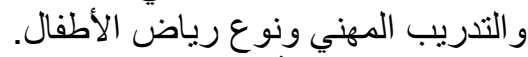

التعريفات الإجرائية معيقات تطبيق تعليم الأونلاين: هي مجموعة الإنية العوامل والمؤثرات الداخلية والخارجية التي تحد من تحقيق الأهداف التربوية في رياض الأطفال خلال تطبيق تعليم الأونلاين والتي حددت بمعوقات الأني متعلقة ب (معتقدات المربية الذاتية،

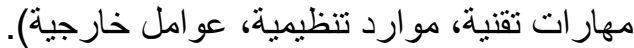

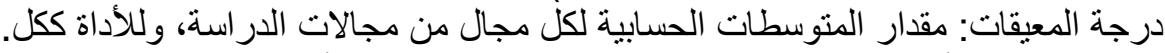

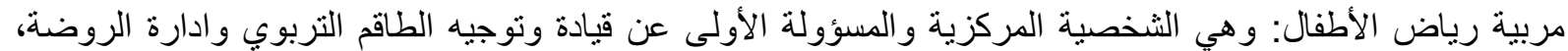

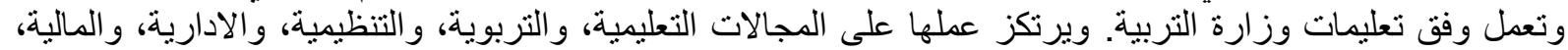

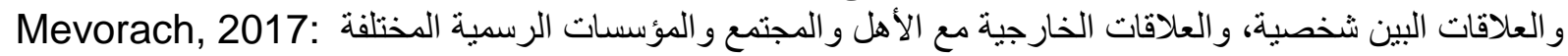
الداخل الفلسطيني: مصطلح يشير إلى المكان الذي يعيش به العرب الفلسطينيين داخل حدود إسر ائيل (ويعرف أيضا بداخل الخط الأخضر، أبي خط الهدنة 1949)، والذين الذين يحملون الجنسية الإسر ائيلية.

$$
\text { الطريقة والإجراعات التمات }
$$

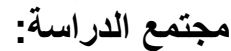

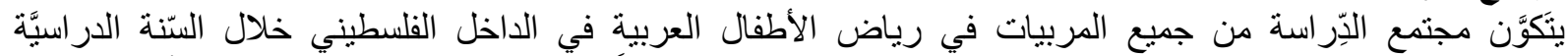
2020/2021 و البالغ عددهم (3138) مربية، وذللك حسب إحصائياًت وزارة التربية داخل الخط الأخضر للعام الإنة

.(2019/2020)

عينة الاراسة:

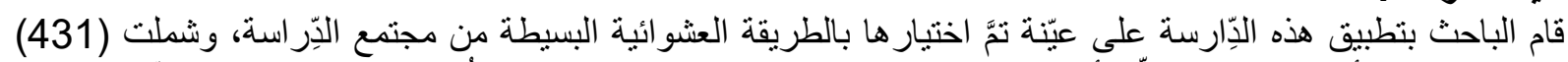

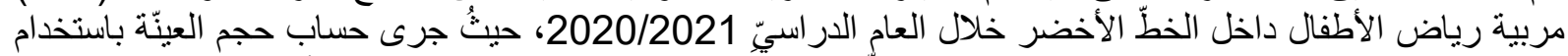

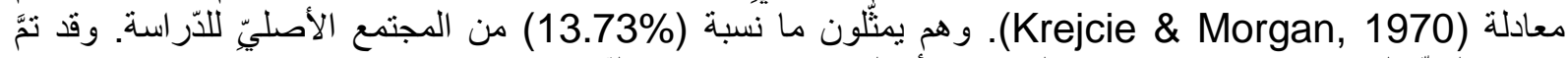

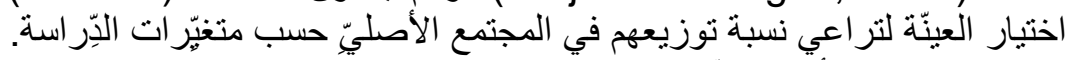

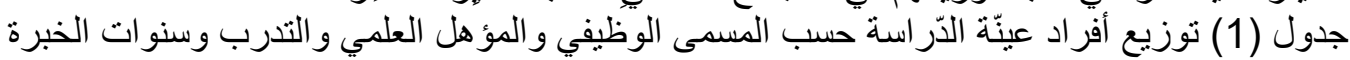

\begin{tabular}{|c|c|c|c|}
\hline النسبة\%\% & التكر ار & الفئات & متغير ات الدر اسة \\
\hline 84.5 & 364 & حكومية & \\
\hline 15.5 & 67 & خاصة & نوع الروضة \\
\hline
\end{tabular}




\section{BARRIERS TO THE INTEGRATION OF ONLINE LEARNING AMONG ARAB}

KINDERGARTEN TEACHERS IN PALESTINIAN COMMUNITY IN ISRAEL

DURING COVID-19 PANDEMIC

\begin{tabular}{|c|c|c|c|}
\hline 100.0 & 431 & المجموع & \\
\hline 63.1 & 272 & بكالوريوس & \multirow{3}{*}{ مؤهل علمي } \\
\hline 36.9 & 159 & در اسات عليا & \\
\hline 100.0 & 431 & المجموع & \\
\hline 22.5 & 97 & 1-10 سنو ات & \multirow{4}{*}{ سنوات الخبرة } \\
\hline 29.0 & 125 & 11-20 سنة & \\
\hline 48.5 & 209 & أكثر من 20 سنة & \\
\hline 100.0 & 431 & المجموع & \\
\hline 80.0 & 345 & نعم & \multirow{3}{*}{ الاكادسيمب لتى استعمالات } \\
\hline 20.0 & 86 & $\gamma$ & \\
\hline 100.0 & 431 & المجموع & \\
\hline
\end{tabular}

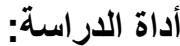

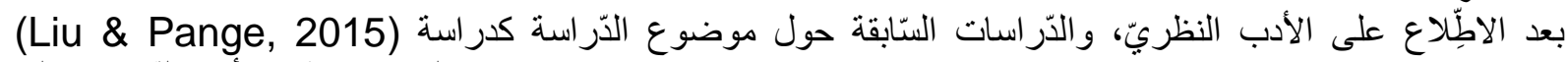

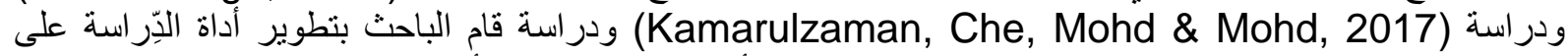
شكل استبانة إلكترونية للكثف عن درجة معيقات تطبيق تعليم الأونلاين في رياض الأطفال.

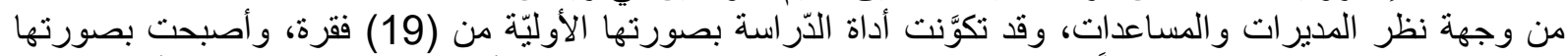

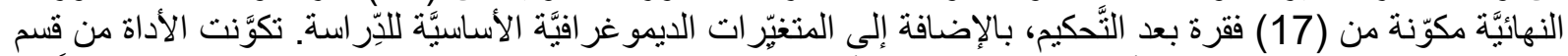

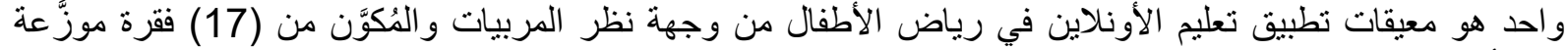

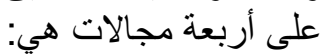

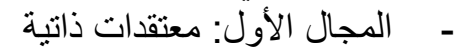
-

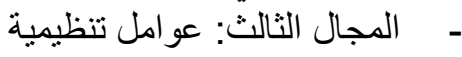

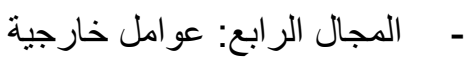

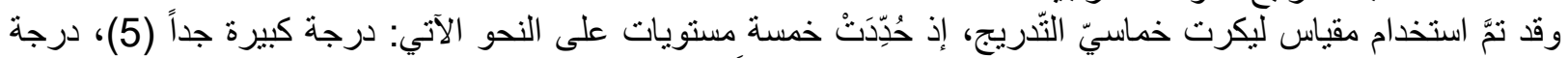

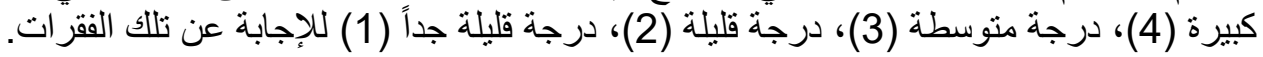

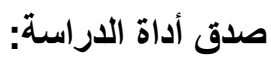

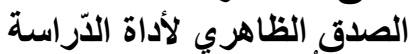

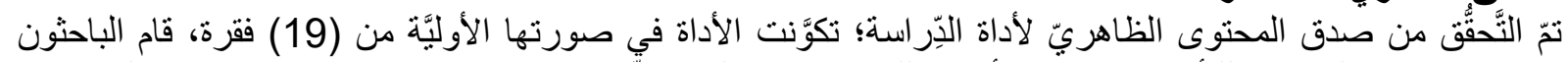

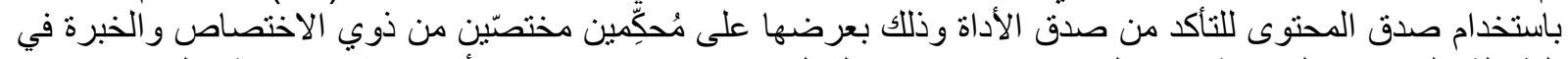

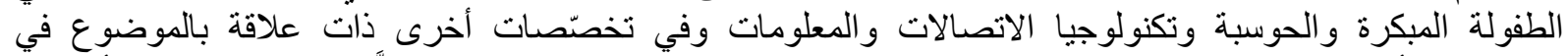

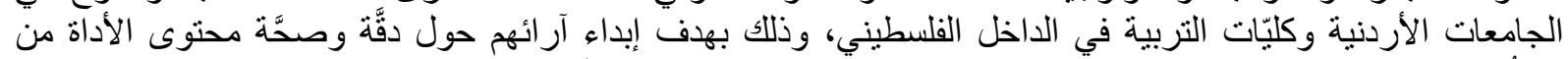

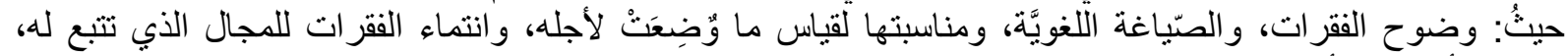

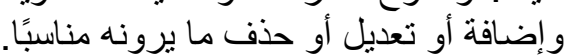

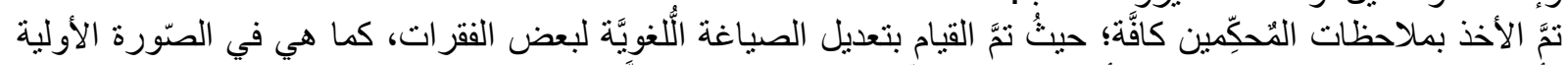

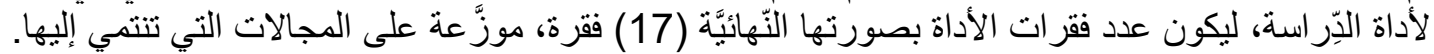

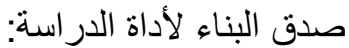
تم تطبيق الاستبانة على عينة استطلاعية من (35) مربية أطفال من مجتمع الدراسة، حيث تم استبعاد التهادهم من عينة

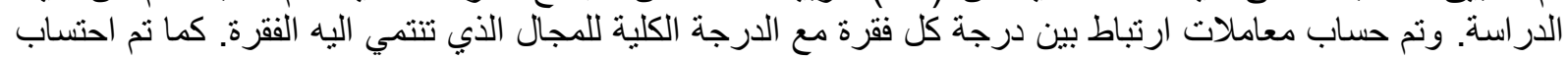

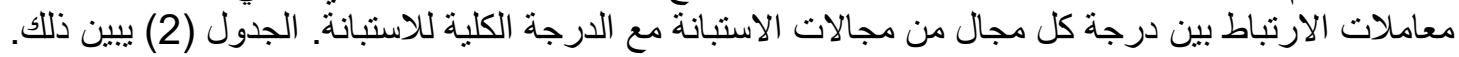


الجدول (2) معاملات ارتباط بيرسون بين مجالات أداة معيقات نطبيق تعليم الأونلاين في رياض الأطفال في الداخل

\begin{tabular}{|c|c|c|c|c|c|}
\hline \multicolumn{6}{|c|}{ الفلسطيني و الاداة ككل } \\
\hline الأداة الكلية & عو امل خارجية & عو امل تنظيمية & مهار ات تقنية & معتقدات ذاتية & المجالات \\
\hline $.797^{\star \star}$ & $.514^{\star \star}$ & $.367^{\star}$ & $.490^{* *}$ & 1 & معتقدات ذاتية \\
\hline $.741^{\star \star}$ & $.372^{*}$ & $.532^{\star \star}$ & 1 & & مهار ات تقنية \\
\hline $.702^{\star \star}$ & $.380^{*}$ & 1 & & & عو امل تتظيمية \\
\hline $.796^{\star \star}$ & 1 & & & & عو امل خاجية \\
\hline
\end{tabular}

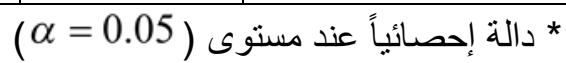

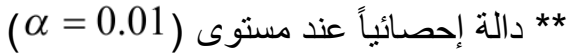

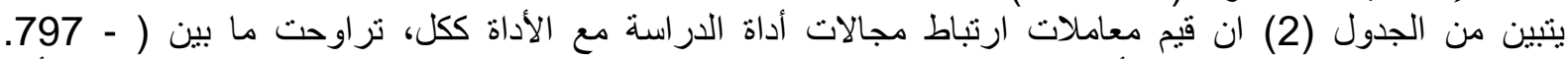

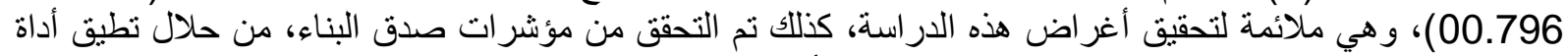

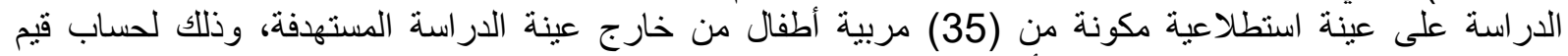

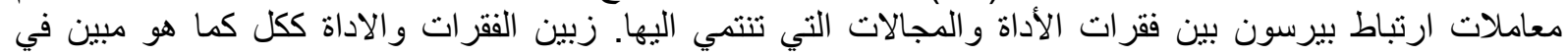

الجدول (3): قيم معاملات ارتباط بيرسون بين فقرات كل مجال مع المجال والاداة الكلية

\begin{tabular}{|c|c|c|c|}
\hline \multicolumn{2}{|c|}{ معامل الارتباط } & \multirow[t]{2}{*}{ الفقرة } & \multirow[t]{2}{*}{ 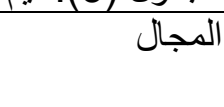 } \\
\hline 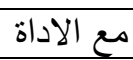 & مع المجال & & \\
\hline $.710^{* \star}$ & $.717^{\star *}$ & عدم ثقة مربية الروضة بالتكنولوجيا و استعمالاتها & \multirow{5}{*}{ 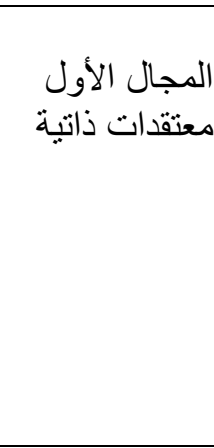 } \\
\hline $.675^{\star \star}$ & $.790^{\star *}$ & التكنولوجية في الروضية بأهمية استعمال الوسائل & \\
\hline $.543^{\star \star}$ & $.523^{\star *}$ & التكنول الرغبا في والتعليم في الروضية المربيات للقيام بدمج & \\
\hline $.443^{* *}$ & $.727^{\star \star}$ & شتعور المربيات بعدم وجيات التعليم فيائدة واضحة من دمج & \\
\hline $.538^{\star \star}$ & $.800^{\star *}$ & 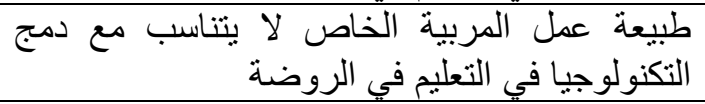 & \\
\hline $.615^{\star \star}$ & $.784^{\star \star}$ & فهر محدود لكيفية دمج الوسائل التكنولوجية في & \multirow{3}{*}{ 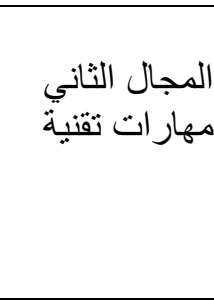 } \\
\hline $.582^{\star *}$ & $.851^{\star *}$ & في استعمال الوسائل التكنولوجية فيل كافية لدى الروضة المربيات & \\
\hline $.630^{\star *}$ & $.850^{\star \star}$ & 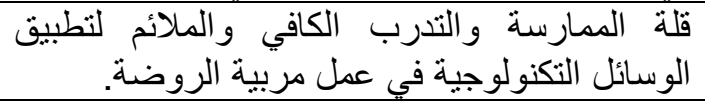 & \\
\hline $.472^{\star *}$ & $.748^{\star \star}$ & قلة الوقت عند المربيات & \multirow{3}{*}{ المو امل تنظيمية } \\
\hline $.659^{\star \star}$ & $.876^{\star \star}$ & وقتاودجاد مهام أكبر محوسبة واستعمال التكنولوجيا بستغرق & \\
\hline $.549^{* \star}$ & $.770^{\star \star}$ & ضغط العمل و وتطلباته & \\
\hline $.510^{\star *}$ & $.731^{\star \star}$ & نقص الدعم التقني & \multirow{6}{*}{ 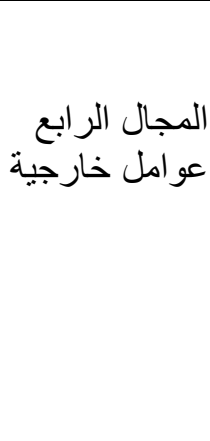 } \\
\hline $.567^{\star \star}$ & $.549^{* *}$ & 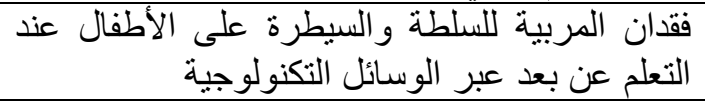 & \\
\hline $.523^{\star \star}$ & $.523^{\star \star}$ & شخصي مع الأطفال عبر ألوسائل التكنولوانية التشاء حوار & \\
\hline $.552^{\star \star}$ & $.680^{\star \star}$ & التكنولوجيا في عملهيل جيد مسبق للمربيات لدمج & \\
\hline $.481^{* \star}$ & $.534^{\star \star}$ & قلة دعم الأهل وتعاونهم ومتابعتهم & \\
\hline $.430^{\star *}$ & $.605^{\star \star}$ & نقص الوسائل و المعدات الإلكترونية او عدم توفرها & \\
\hline
\end{tabular}

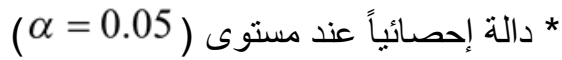

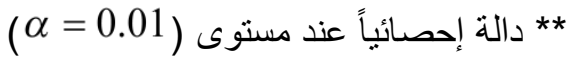




\section{BARRIERS TO THE INTEGRATION OF ONLINE LEARNING AMONG ARAB \\ KINDERGARTEN TEACHERS IN PALESTINIAN COMMUNITY IN ISRAEL \\ DURING COVID-19 PANDEMIC}

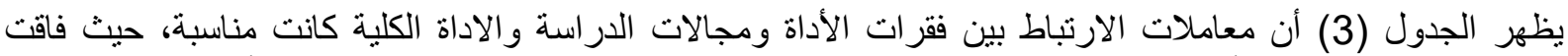

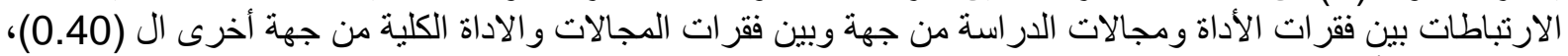
و هي ملائمة لأغر اض تحقيق الأرداة الهداف الدراسة الحالية.

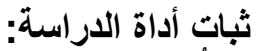

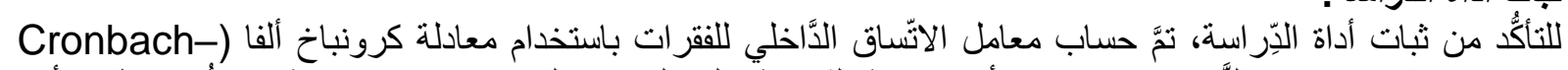
(Alpha

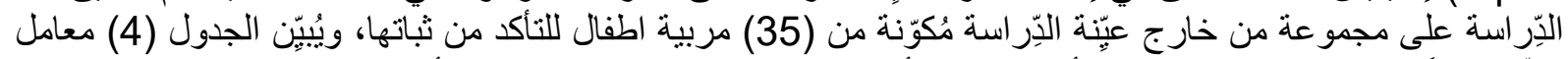

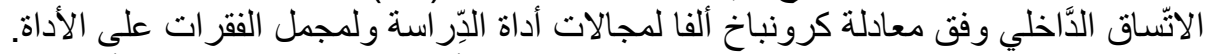

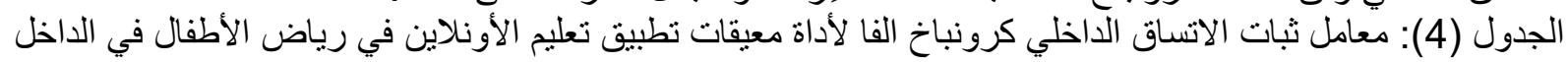
الفلسطيني ككل ومجالاتها

\begin{tabular}{|c|c|c|c|}
\hline الداخلي $\quad$ الاتساق & عدد الفقر ات & \multicolumn{2}{|c|}{ المقياس ومجالاته } \\
\hline .749 & 5 & معتقدات ذاتية & المجال الأول \\
\hline .448 & 3 & مهار ات تقنية & المجال الثاني \\
\hline .661 & 7 & عو امل تنظيمية & المجال الثالث \\
\hline .716 & 3 & عو امل خارجية & المجال الرابع \\
\hline .849 & 18 & & الأداة الكلية \\
\hline
\end{tabular}

يُيِيِّن الجدول (4) قِيَم معامل كرونباخ ألفا لفقرات أداة درجة معيقات تطبيق تعليم الأونلاين لدى مربيات رياض الأطفال

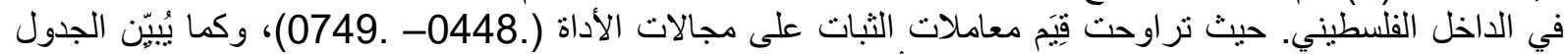

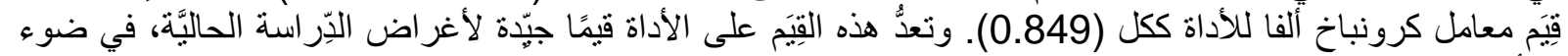

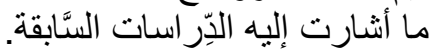

\section{تصحيح أداة الدراسة}

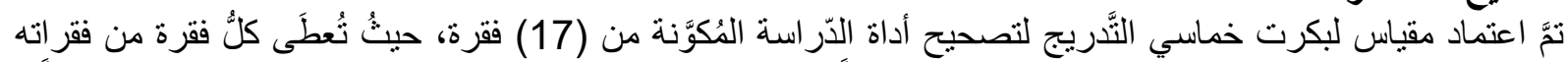

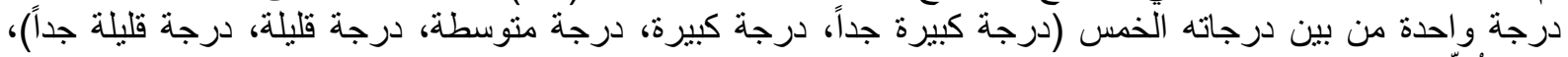

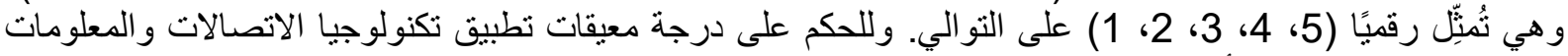
في التدريس في رياض رئا (5ان الأطفال سيتم استخدام المعادلة الاتية لتحديد معيار الحكم على الدرجة وهي: طول الفئل الفئة = (أعلى قيمة في تدريج المقياس - أدنى

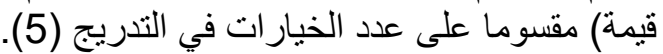

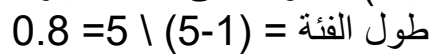

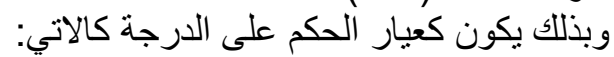

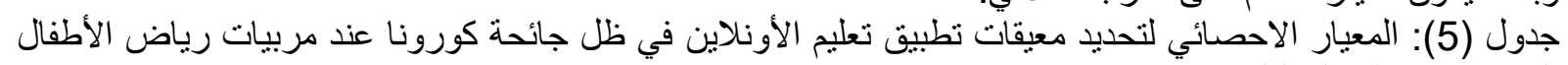

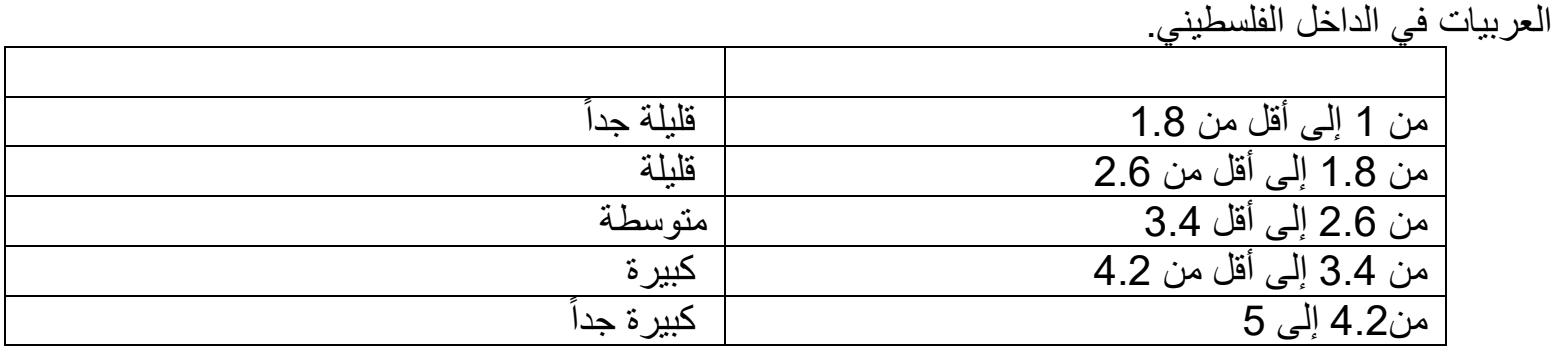




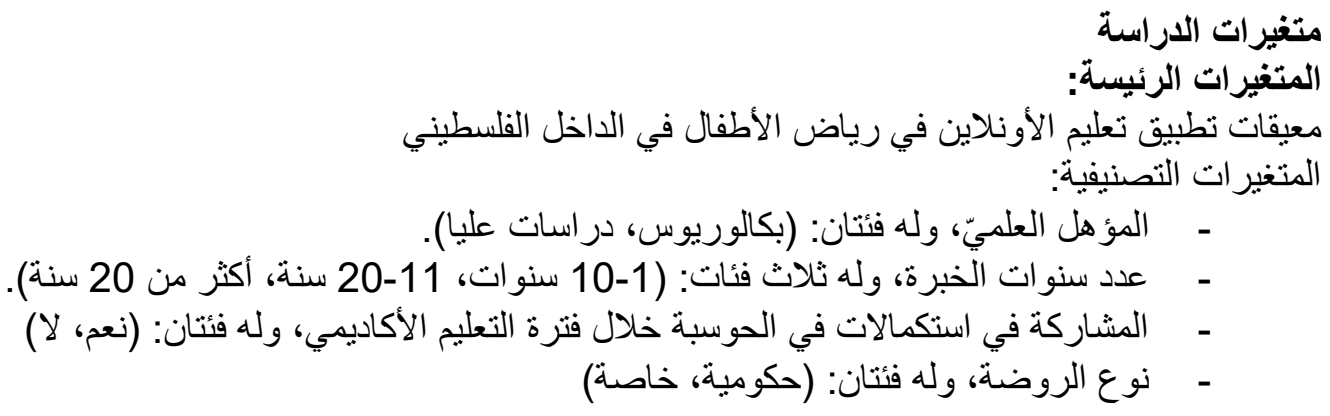

أساليب المعالجة الإحصائية:

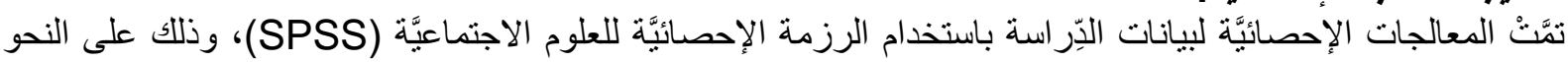

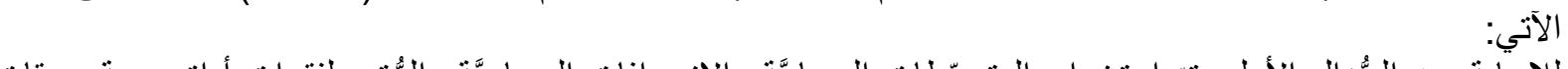
للإجابة عن الليُّؤال الأول، نّمّ استخر اج المنوسّطات الحسابيَّة و الانحر افات المعياريَّة و الرُّتب لفقرات أداة درجة معيقات

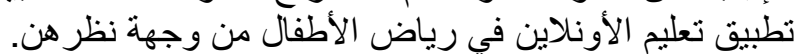

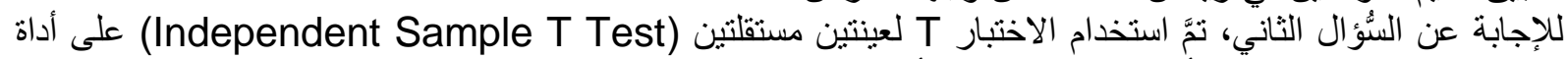

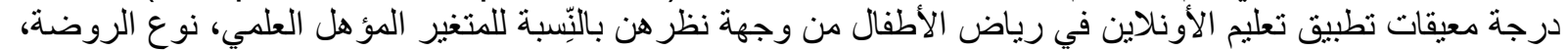

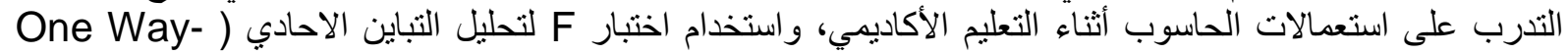
(Anova

نتائج الاراسة: هدفت الدراسة الحالية إلى فحص التحديات والعو امل المعيقة لتطبيق تعليم الأونلاين في ظل جائحة كورونا عند مربيات

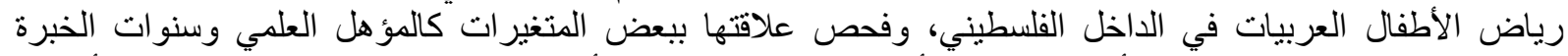

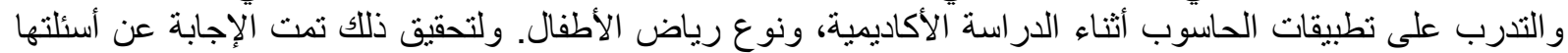

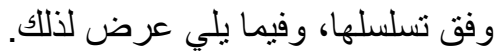
نتائج السؤ ال الأول الذيم نص علي على: ما درجة معيقات تطبيق تعليم الأونلاين في ظل جائحة كورونا عند مربيات رياض

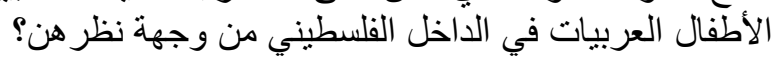

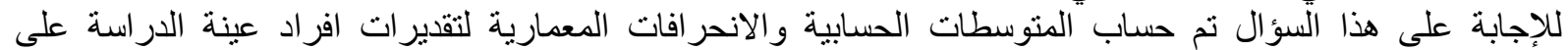

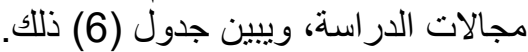

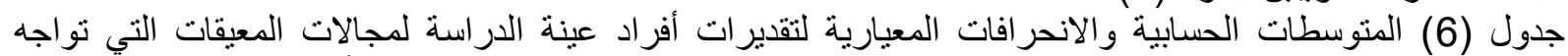
مربيات رياض الأطفال في تطبيق تعليم الأونلاين في عملهن في الداخل الاخل الفلسطيني مرنبة تنازلياً.

\begin{tabular}{|c|c|c|c|c|c|}
\hline الدرجة & الرنبة & الانحر اف المعياريّ & المتوسط الحسابيّ & المجالات & 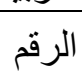 \\
\hline متوسطة & 1 & .88 & 3.32 & عو امل خارجية & 1 \\
\hline متوسطة & 2 & 1.06 & 3.11 & مهار ات تقنية & 2 \\
\hline متوسطة & 3 & 1.10 & 2.82 & عو امل تتظيمية & 3 \\
\hline قليلة & 4 & .91 & 2.18 & معتقدات ذاتية & 4 \\
\hline & متوسطة & .76 & 2.86 & \multicolumn{2}{|c|}{ الدرجة الكلية } \\
\hline
\end{tabular}

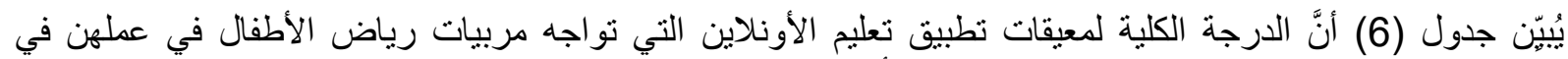

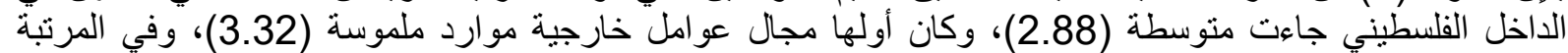

الأخيرة مجال معتقدات ذاتية (2.18).

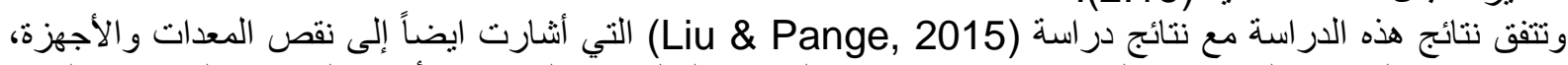

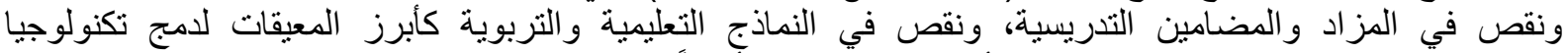

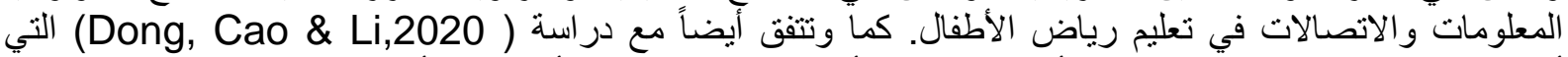

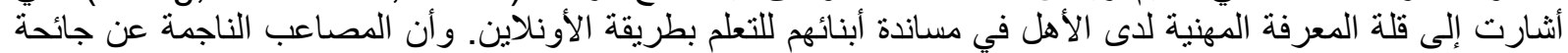
كورونا التي واجهت الأهل ساهمت في معاناتهم ومقاومتهم للتعلم بطريقة الأونلاين من البيت، و عدم تقبلهم وجهوزيتهم

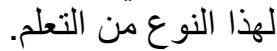




\section{BARRIERS TO THE INTEGRATION OF ONLINE LEARNING AMONG ARAB \\ KINDERGARTEN TEACHERS IN PALESTINIAN COMMUNITY IN ISRAEL \\ DURING COVID-19 PANDEMIC}

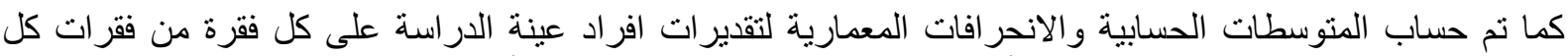
مجال من مجالات معيقات تطبيق تعليم الأونلاين التي تواجه مربيات التيات الفيات رياض الأطفال في عملهن في الداخل الفلسطيني

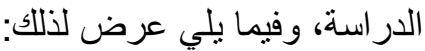

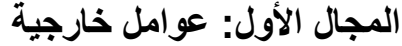

تم حساب المتوسطات الحسابية والانحر افات المعيارية لاستجابات أفراد عينة الدراسة لفقرات مجال عوامل خارجية كما

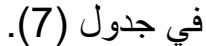
جذول (7) المنوسطات الحسابية والانحر افات المعيارية لتقديرات أفراد عينة الدراسة لمجال عوامل خارجية مرتبة

\begin{tabular}{|c|c|c|c|c|c|}
\hline 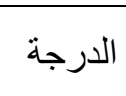 & الرُّتبة & 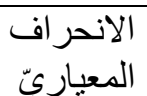 & الحستيّ الحسيّ & الفقرة & 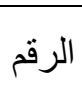 \\
\hline كبيرة & 1 & 1.14 & 3.65 & قلة دعم الأهل وتعاونهم ومتابعتهم & 13 \\
\hline كبيرة & 2 & 1.15 & 3.55 & التكنولو اعداد في وتأهيل جيد مسبق للمربيات ل لدمج & 16 \\
\hline كبيرة & 3 & 1.21 & 3.44 & نقص الوسائلّ و المعدات الإلكترونية او عدم توفرها & 17 \\
\hline متوسطة & 4 & 1.17 & 3.26 & نقص الدعم التقني & 15 \\
\hline متوسطة & 5 & 1.25 & 3.09 & 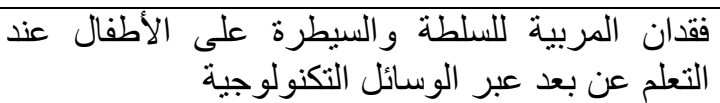 & 8 \\
\hline متوسطة & 6 & 1.26 & 2.91 & 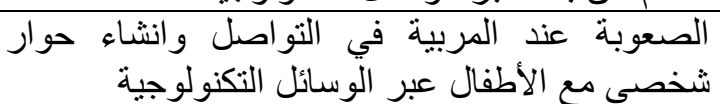 & 9 \\
\hline متوسطة & & .88 & 3.32 & الدرجة الكلية & \\
\hline
\end{tabular}

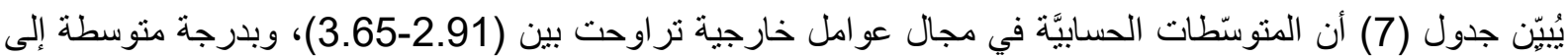

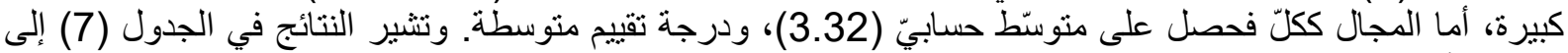

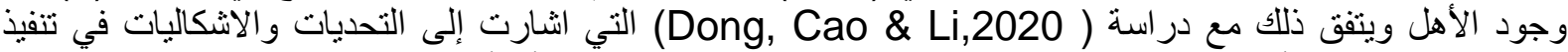

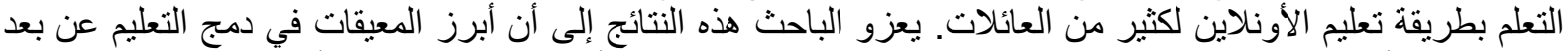

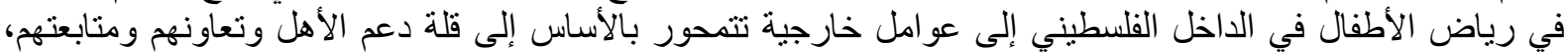

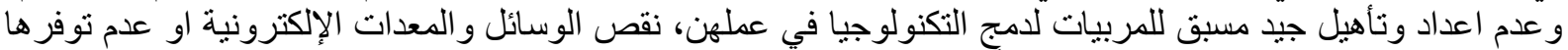

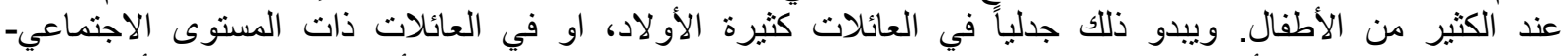

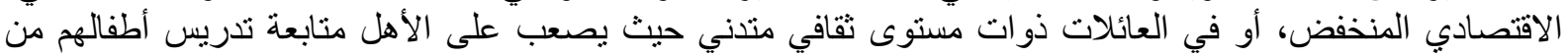

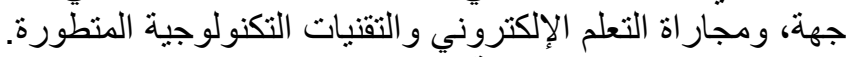

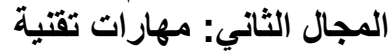
تم حساب المتوسطات الحسابية والانحر افتات المعيارية لاستجابات أفراد عينة الدراسة لفقرات مجال مهارات تقنية في

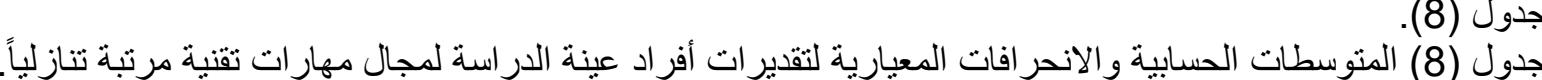

\begin{tabular}{|c|c|c|c|c|c|}
\hline الدرجة - الد & 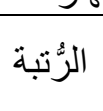 & الانحر افيّ & الحسابيّ & الفقرة & 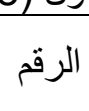 \\
\hline متوسطة & 1 & 1.20 & 3.27 & التكنولو الممارسة في و عمل مربية التروضية. والكانئم لتطبيق الوسائل & 10 \\
\hline متوسطة & 2 & 1.17 & 3.27 & مهتعمال الوسائل التكنولوفية في في الرية لدى المربية & 7 \\
\hline متوسطة & 3 & 1.24 & 2.77 & فهم محدود لكيفية دمج الوسائل التنكنولوجية في التعليم & 6 \\
\hline متوسطة & & 1.06 & 3.11 & 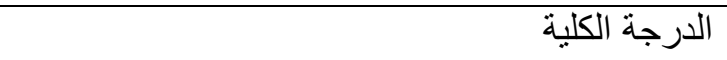 & \\
\hline
\end{tabular}


يُيِيِّن جدول (8) أن المتوسّطات الحسابيَّة في مجال مهار ات تقنية تراوحت بين (3.11) (2.77-3.27)، وبدرجة متوسطة، أما

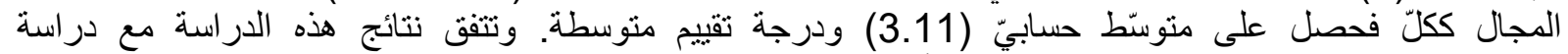
(Mynarikova \& Novotny, 2020)

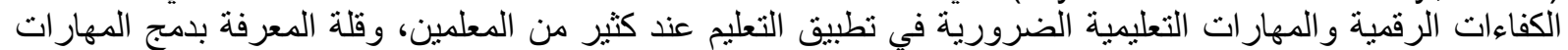

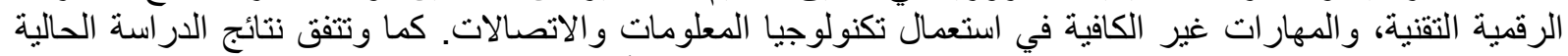

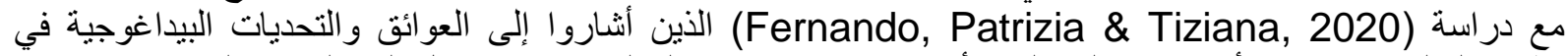

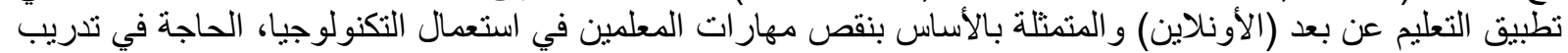

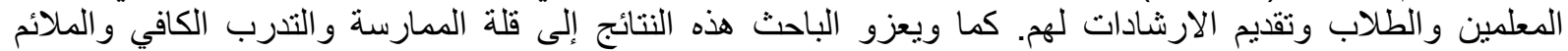

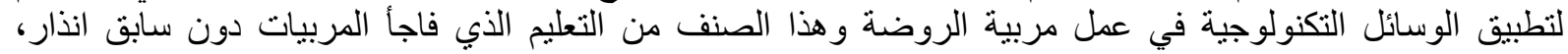
بالإضافة إلى مهارات تكنولوجية محدودة ومعرفة غير كافية لإلى لإى كثير من جمهور المربيات في استعمال الوسائل

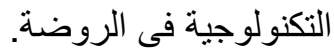
المجال الثالث: عوامل في تلزيمية تم حساب المتوسطات الحسابية والانحر افات المعيارية لاستجابات أفراد عينة الدراسة لفقرات مجال عوامل تنظيمية كما في جدول (9). جذول (9) المنوسطات الحسابية والانحرافات المعيارية لتقديرات أفراد عينة الدراسة لمجال عوامل تنظيمية مرتبة

\begin{tabular}{|c|c|c|c|c|c|}
\hline الدرجة & الرُّتبة & 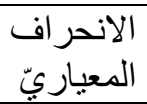 & الحستيّ المتيّ & الفقرة & 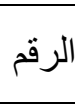 \\
\hline متوسطة & 1 & 1.34 & 3.20 & وقتا وجهاد مهاح أكبر محوسبة واستعمال التكنولوجيا يستغرق & 12 \\
\hline متوسطة & 2 & 1.30 & 3.17 & ضغط العمل و ونطلباته & 14 \\
\hline متوسطة & 3 & 1.27 & 2.11 & قلة الوقت عند المربيات & 11 \\
\hline متوسطة & & 1.10 & 2.82 & الدرجة الكلية & \\
\hline
\end{tabular}

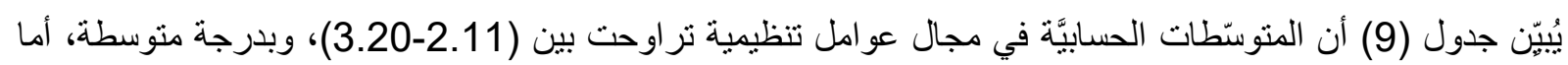

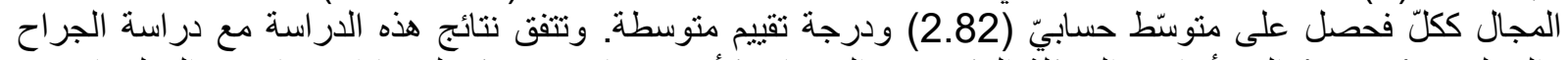

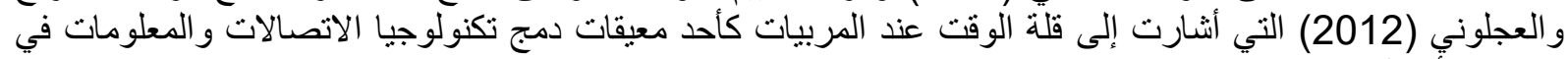

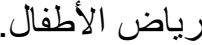

المجال الر ابع: معتقدات ذاتية

نم حساب المنوسطات الحسابية و الانحر افات المعيارية لاستجابات أفر اد عينة الدر اسة لفقرات مجال معتقدات ذاتية كما في

جدول (10).

جدول (10) المنوسطات الحسابية والانحر افات المعيارية لتقديرات أفراد عينة الدراسة لمجال معتقدات ذاتية مرتبة

\begin{tabular}{|c|c|c|c|c|c|}
\hline 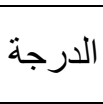 & الرُّنة & المعياريّ اف المحر & المسابيّ المتيّ & 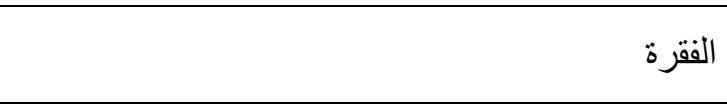 & الرقم \\
\hline قليلة & 1 & 1.21 & 2.44 & طبيعة عمل المربية الخاص لا لا يتناسب مع دمج & 5 \\
\hline 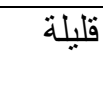 & 2 & 1.19 & 2.27 & 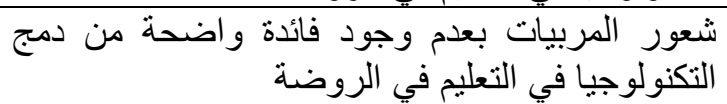 & 4 \\
\hline قليلة & 3 & 1.08 & 2.05 & 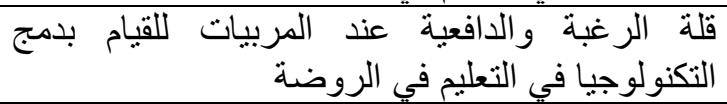 & 3 \\
\hline قليلة & 4 & 1.16 & 2.18 & عدم ثقة مربية الروضة بالتكنولوجيا و استعمالاتها & 1 \\
\hline 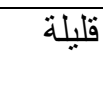 & 5 & 1.12 & 1.97 & التكنولو شية في الروضية المربية بأهمية استعمال الوسائل & 2 \\
\hline 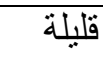 & & .91 & 2.18 & الدرجة الكلية & \\
\hline
\end{tabular}

يُيِيِّن جدول (10) أن المنوسّطات الحسابيَّة في مجال معتقدات ذاتية نراوحت بين (18.97-2.44)، وبدرجة قليلة، أما

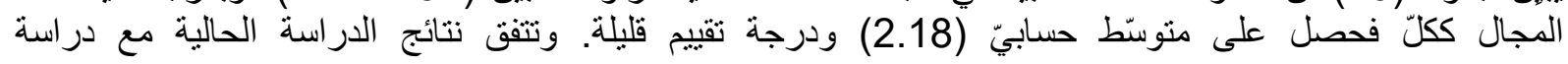




\section{BARRIERS TO THE INTEGRATION OF ONLINE LEARNING AMONG ARAB \\ KINDERGARTEN TEACHERS IN PALESTINIAN COMMUNITY IN ISRAEL \\ DURING COVID-19 PANDEMIC}

(Blackwell, Lauricella \& Wartella, 2014)

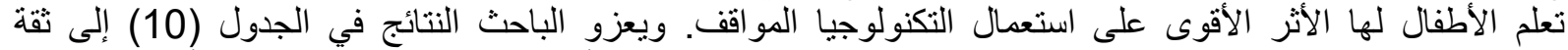

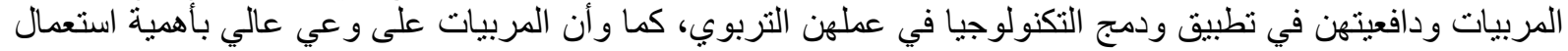

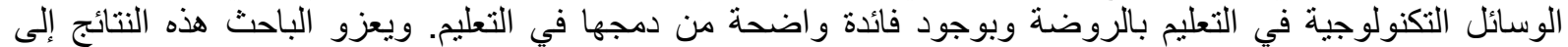

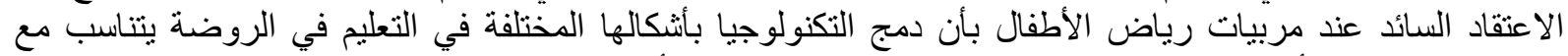

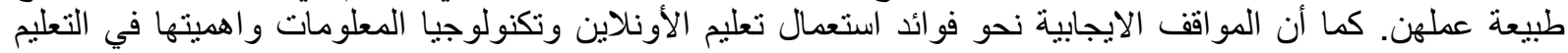
تساهم في تسهيل استعماله وناجعته.

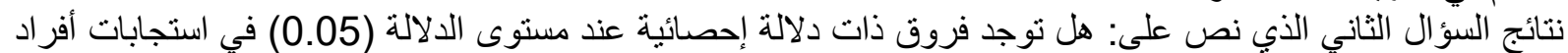

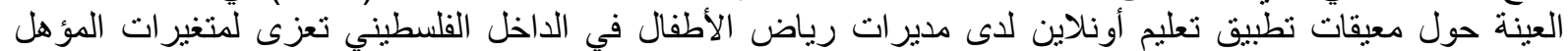

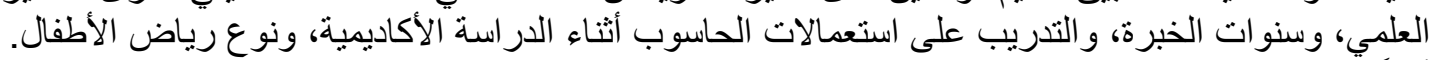

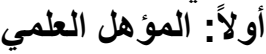

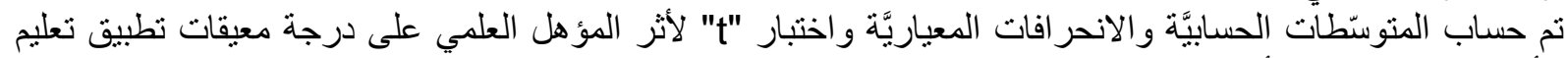

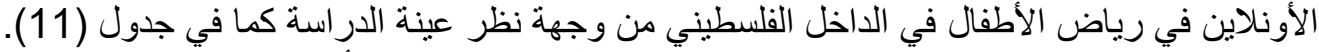

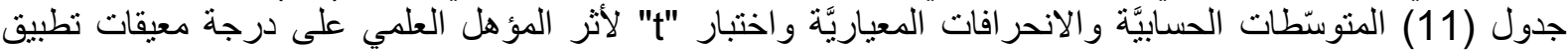

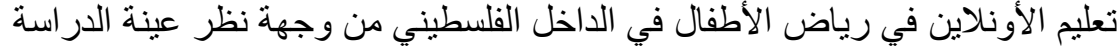

\begin{tabular}{|c|c|c|c|c|c|c|c|c|}
\hline الدلالة & الحرجيةت & قا & الانحياري اف & الحسابي & العدد ال العد & المؤهل العلمي & مجالاتة & الرقم \\
\hline \multirow[t]{2}{*}{.151} & \multirow[t]{2}{*}{429} & \multirow[t]{2}{*}{1.437} & .91 & 2.23 & 272 & بكالوريوس & \multirow[b]{2}{*}{ عو امل خارجية } & \multirow[t]{2}{*}{1} \\
\hline & & & .89 & 2.10 & 159 & در اسات عليا & & \\
\hline \multirow[t]{2}{*}{.699} & \multirow[t]{2}{*}{429} & \multirow[t]{2}{*}{-.387} & 1.03 & 3.09 & 272 & بكالوريوس & \multirow[t]{2}{*}{ مهار ات تقنية } & \multirow[t]{2}{*}{2} \\
\hline & & & 1.11 & 3.13 & 159 & در اسات عليا & & \\
\hline \multirow[t]{2}{*}{.616} & \multirow[t]{2}{*}{429} & \multirow[t]{2}{*}{.502} & 1.10 & 2.84 & 272 & بكالوريوس & \multirow[t]{2}{*}{ عو امل تتظيمية } & \multirow[t]{2}{*}{3} \\
\hline & & & 1.09 & 2.79 & 159 & در اسات عليا & & \\
\hline \multirow[t]{2}{*}{.604} & \multirow[t]{2}{*}{429} & \multirow[t]{2}{*}{.519} & .85 & 3.33 & 272 & بكالوريوس & \multirow[t]{2}{*}{ معتقدات ذاتية } & \multirow[t]{2}{*}{4} \\
\hline & & & .94 & 3.28 & 159 & در اسات عليا & & \\
\hline \multirow[t]{2}{*}{.453} & \multirow[t]{2}{*}{429} & \multirow[t]{2}{*}{.751} & .73 & 2.88 & 272 & بكالوريوس & \multirow{2}{*}{\multicolumn{2}{|c|}{ الدرجة الكلية }} \\
\hline & & & .80 & 2.82 & 159 & در اسات عليا & & \\
\hline
\end{tabular}

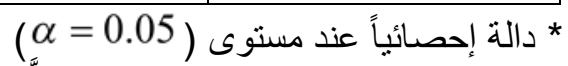

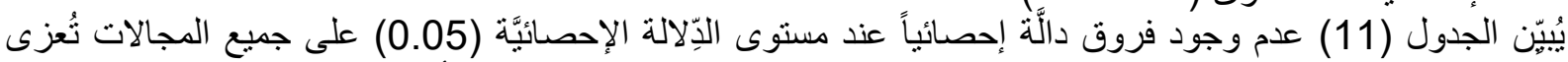

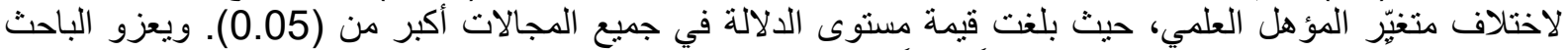

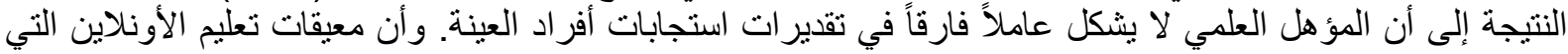

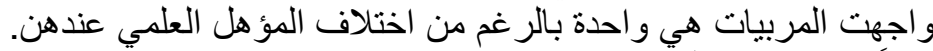

ثُانياً: نوع الروضة الربات

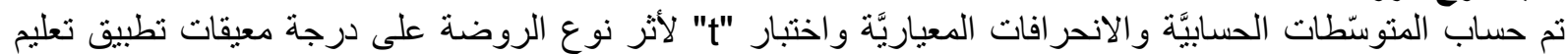

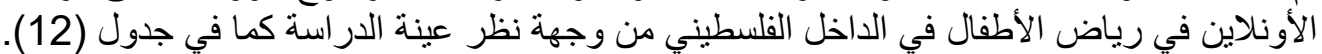

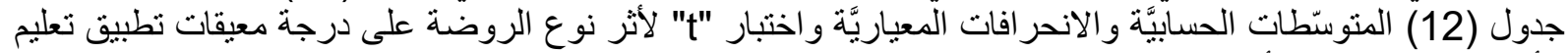

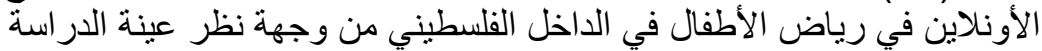

\begin{tabular}{|c|c|c|c|c|c|c|c|c|}
\hline مستوى & الررجية & قيمة & الانحرياري & الحسابي & العدد & نوع الروضة & الاستبانة & الرقم \\
\hline \multirow[t]{2}{*}{.127} & \multirow[t]{2}{*}{429} & \multirow[t]{2}{*}{1.528} & .91 & 2.21 & 364 & حكومية & \multirow[t]{2}{*}{ عو امل خارجية } & \multirow[t]{2}{*}{1} \\
\hline & & & .87 & 2.03 & 67 & خاصة & & \\
\hline \multirow[t]{2}{*}{.654} & \multirow[t]{2}{*}{429} & \multirow[t]{2}{*}{.449} & 1.06 & 3.19 & 364 & حكومية & \multirow[t]{2}{*}{ مهار ات تقنية } & \multirow[t]{2}{*}{2} \\
\hline & & & 1.05 & 3.05 & 67 & خاصة & & \\
\hline \multirow[t]{2}{*}{.071} & \multirow[t]{2}{*}{429} & \multirow[t]{2}{*}{1.811} & 1.11 & 2.86 & 364 & حكومية & \multirow[t]{2}{*}{ عو امل تتظيمية } & \multirow[t]{2}{*}{3} \\
\hline & & & 1.03 & 2.60 & 67 & خاصة & & \\
\hline
\end{tabular}




\begin{tabular}{|c|c|c|c|c|c|c|c|c|}
\hline \multirow[t]{2}{*}{.595} & \multirow[t]{2}{*}{429} & \multirow[t]{2}{*}{-.532} & .89 & 3.30 & 364 & حكومية & \multirow[t]{2}{*}{ معتقدات ذاتية } & \multirow[t]{2}{*}{4} \\
\hline & & & .83 & 3.36 & 67 & خاصة & & \\
\hline \multirow[t]{2}{*}{.375} & 429 & .889 & .77 & 2.87 & 364 & حكومية & \multirow{2}{*}{\multicolumn{2}{|c|}{ الدرجة الكلية }} \\
\hline & & & .65 & 2.78 & 67 & خاصة & & \\
\hline
\end{tabular}

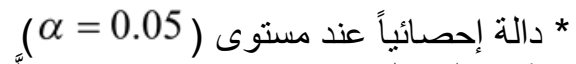

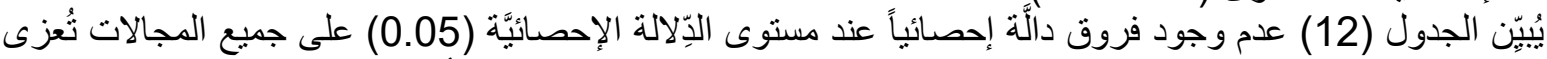

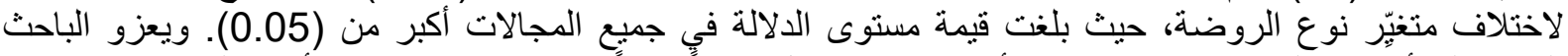

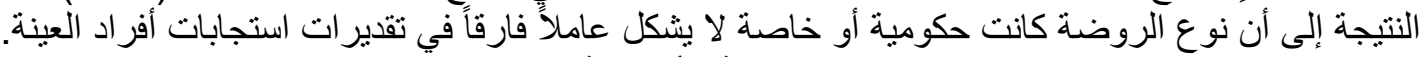

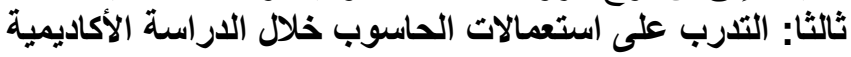

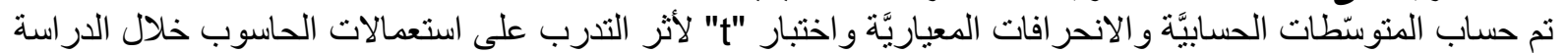

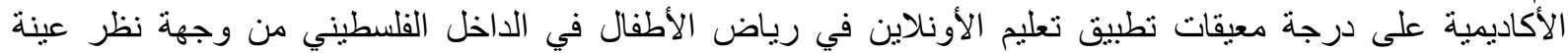

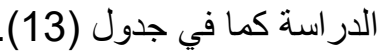

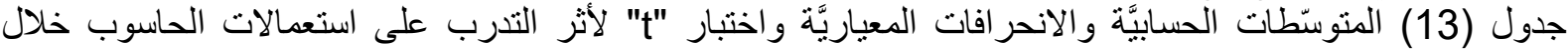

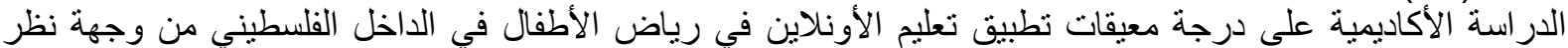

\begin{tabular}{|c|c|c|c|c|c|c|c|c|}
\hline & & & & & & & مة & عينه آ \\
\hline مستوى & درجات & قيمة & الانحر اف & المتوسط & العدد & التدرب & مجالات & الرقم \\
\hline الدلالة & الحرية & $\mathrm{t}$ & المعياري & الحسابي & & & الاستبانة & \\
\hline $.012^{*}$ & 429 & -2.525 & .88 & 2.13 & 345 & 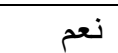 & عو امل خارجية & 1 \\
\hline & & & .96 & 2.41 & 86 & $y$ & & \\
\hline $.000^{*}$ & 429 & -4.982 & 1.06 & 2.99 & 345 & نعم & مهار ات تقنية & 2 \\
\hline & & & .91 & 3.56 & 86 & $y$ & & \\
\hline .188 & 429 & -1.318 & 1.10 & 2.79 & 345 & نعم & عوامل تنظيمية & 3 \\
\hline & & & 1.11 & 2.96 & 86 & $y$ & & \\
\hline $.012^{*}$ & 429 & -2.518 & .89 & 3.26 & 345 & نعم & معتقدات ذاتية & 4 \\
\hline & & & .80 & 3.53 & 86 & $y$ & & \\
\hline $.001^{*}$ & 429 & -3.381 & .76 & 2.79 & 345 & نعم & الكلية & الدرجا \\
\hline & & & .69 & 3.10 & 86 & $y$ & & \\
\hline
\end{tabular}

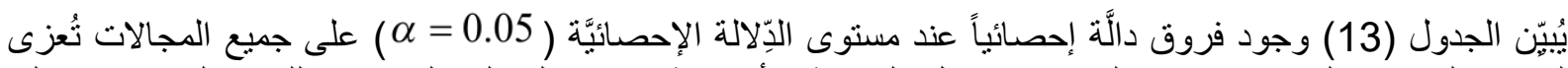

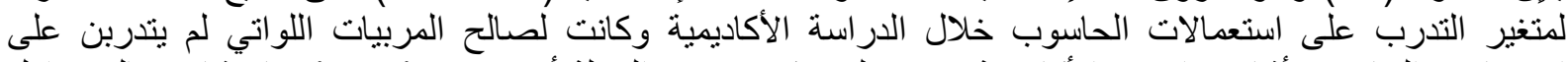

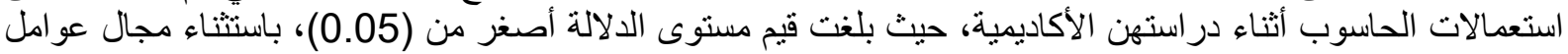

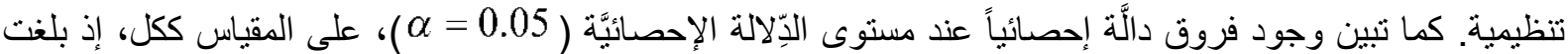

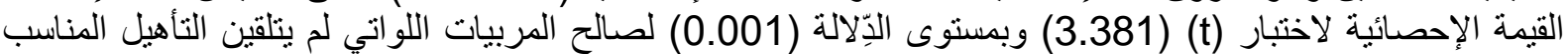

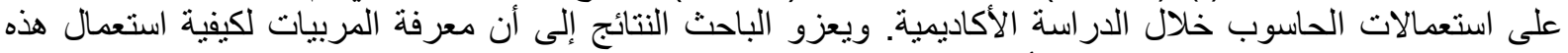

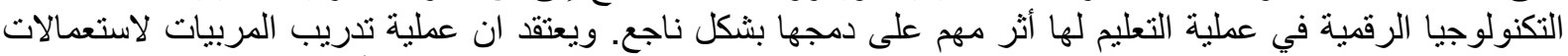

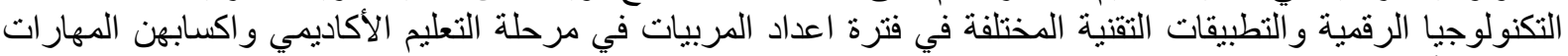

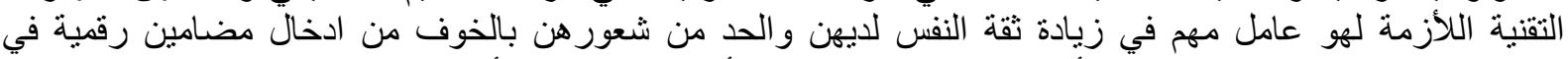

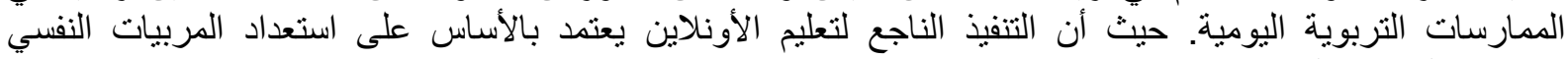

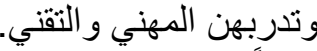
رابعاً: سنوات الخبرة الخبرة

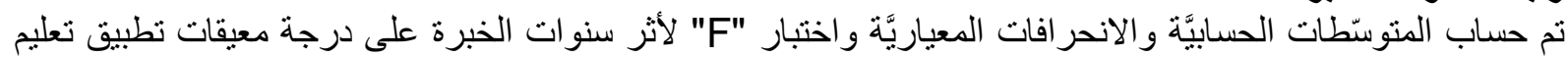

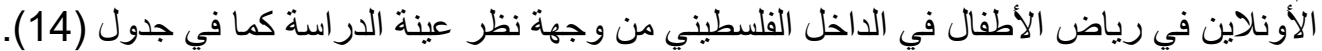

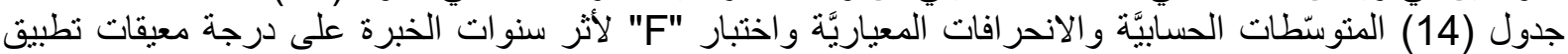

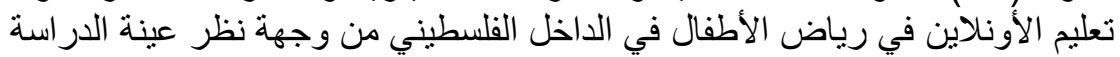


KINDERGARTEN TEACHERS IN PALESTINIAN COMMUNITY IN ISRAEL

DURING COVID-19 PANDEMIC

\begin{tabular}{|c|c|c|c|c|c|c|c|c|}
\hline الدلالة & الحرجية & قيمة & الانحر اف المعياري & الحستوسطي & العدد ال العد & سنوات الخبرة & الاستبانة & الرقم \\
\hline \multirow[t]{3}{*}{.954} & \multirow[t]{3}{*}{2,428} & \multirow[t]{3}{*}{.047} & .84 & 2.19 & 97 & 1-10 سنو ات & \multirow[t]{3}{*}{ عو امل خارجية } & \multirow[t]{3}{*}{1} \\
\hline & & & .95 & 2.20 & 125 & 11-20 سنة & & \\
\hline & & & .91 & 2.17 & 209 & 20 سنة فأكثر & & \\
\hline \multirow[t]{3}{*}{.541} & \multirow[t]{3}{*}{2,428} & \multirow[t]{3}{*}{.614} & .98 & 3.19 & 97 & 1-10 سنو ات & \multirow[t]{3}{*}{ مهار ات تقنية } & \multirow[t]{3}{*}{2} \\
\hline & & & 1.06 & 3.04 & 125 & 11-20 سنة & & \\
\hline & & & 1.09 & 3.11 & 209 & 20 سنة فأكثر & & \\
\hline \multirow[t]{3}{*}{$.000^{*}$} & \multirow[t]{3}{*}{2,428} & \multirow[t]{3}{*}{10.965} & 1.08 & 2.95 & 97 & 1-10 سنو ات & \multirow[t]{3}{*}{ عو امل تتظيمية } & \multirow[t]{3}{*}{3} \\
\hline & & & 1.08 & 3.13 & 125 & 11-20 سنة & & \\
\hline & & & 1.06 & 2.58 & 209 & 20 سنة فأكثر & & \\
\hline \multirow[t]{3}{*}{$.002^{*}$} & \multirow[t]{3}{*}{2,428} & \multirow[t]{3}{*}{6.160} & .82 & 3.57 & 97 & 1-10 سنو ات & \multirow[t]{3}{*}{ معتقدات ذاتية } & \multirow[t]{3}{*}{4} \\
\hline & & & .92 & 3.32 & 125 & 11-20 سنة & & \\
\hline & & & .87 & 3.19 & 209 & 20 سنة فأكثر & & \\
\hline \multirow[t]{3}{*}{$.044^{*}$} & \multirow[t]{3}{*}{2,428} & \multirow[t]{3}{*}{3.152} & .67 & 2.99 & 97 & 1-10 سنو ات & \multirow{3}{*}{\multicolumn{2}{|c|}{ الارجة الكلية }} \\
\hline & & & .83 & 2.91 & 125 & 11-20 سنة & & \\
\hline & & & .74 & 2.77 & 209 & 20 سنة فأكثر & & \\
\hline
\end{tabular}

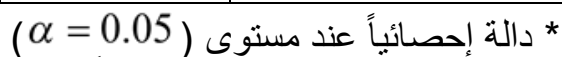

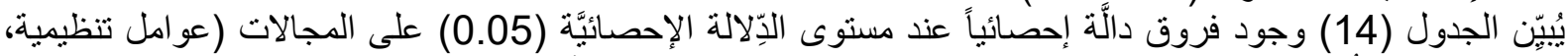

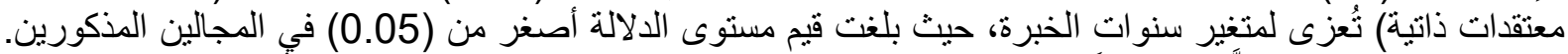

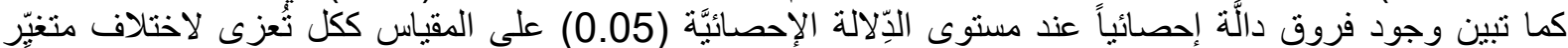

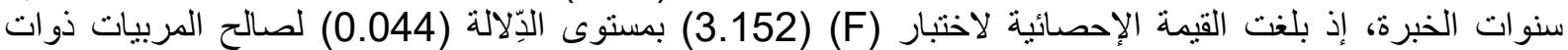

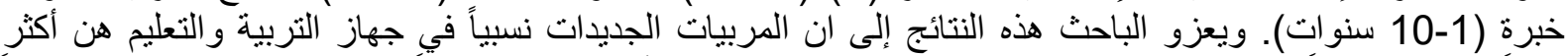

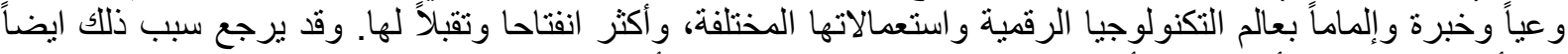

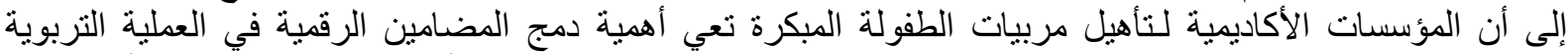

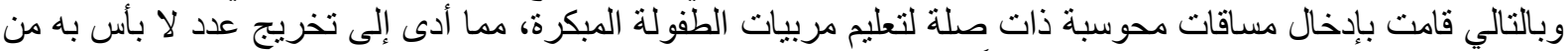

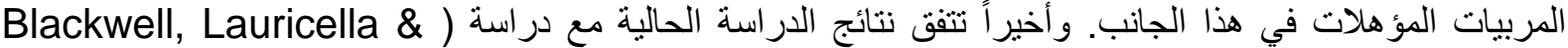
(Wartella, 2014 و والمعلومات وتعليم الأونلاين.

التوصيات:

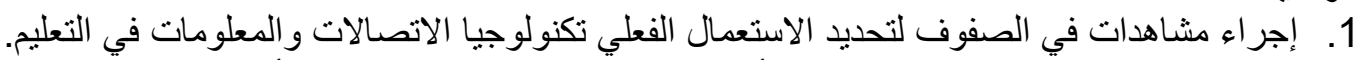

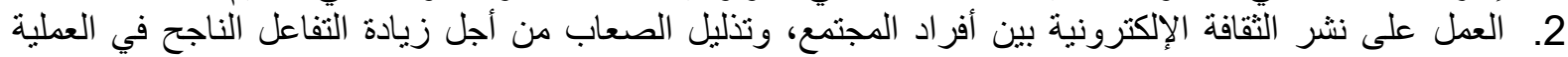
3. أهمية التدريب المكثف لاستعمال تكنولوجيا الاتصالات والمعلومات وبالتالي تحقيق تعليم الأونلاين بصورة ناجعة و إبداعية. 4. على وزارة التربية استخلاص العبر من هذه التجربة وبناء خطط عملية واضحة المعالم لمجابهة سناريوهات مستقبلية لتطبيق تعليم الأونلاين بطريقة أكثر نجاعة ونجاحاً.

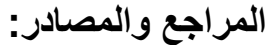
الجراح، عبد الهادي علي والعجلوني، خالد إبراهيم. (2012). درجة استخدام معلمات رياض الأطفال في عمان

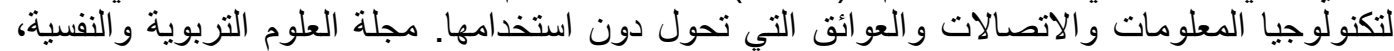

.129-103، (1)13 
حناوي، مجدي ونجم، روان. (2019). جاهزية معلمي المرحلة الأساسية الأولى في المدارس الحكومية في مديرية تربية نابلس لتوظيف التعلم الإلكتروني " الكفايات والاتجاهات ولات والمعيقات"، مجلة الجامعة العربية الامريكية

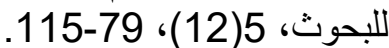
مركز الملك سلمان للإغاثة و الاعمال الإنسانية. (2012) (2020). التعلم عن بعد: مفهومه و أدو اته واستر اتيجياته، اليونسكو. Blackwell, C.K., Lauricella, A.R., and Wartella, E. (2014). Factors influencing digital technology use in early childhood education. Computer \& Education, 77, 82-90.

Dong, C., Cao, S., \& Li, H. (2020). Young children's online learning during COVID-19 pandemic: Chinese parents' beliefs and attitudes. Children and Youth Services Review, 118, 1-20.doi https://doi.org/10.1016/j.childyouth.2020.105440

Fox, J.L., Diezmann, C.M., and Lamb, J. (2016) Early childhood teachers' integration of ICTs: Intrinsic and extrinsic barriers. 39th Annual Conference of the Mathematics Education Research Group of Australasia. Adelaide, Australia: Mathematics Education Research Group of Australasia. pp. 246 $-253$

Kamarulzaman, K., Che, A., Mohd, N. \& Mohd, N. (2017). Teachers' level of ICT integration in teaching and learning: a survey in Malaysian private preschool. AIP Conference Proceedings.

Kim, J. (2020). Learning and teaching online during Covid-19: Experiences of student teachers in an early childhood education practicum. International Journal of Early Childhood, 52: 145-158, https://doi.org/10.1007/s13158-020-

00272-6.

Krejcie, R. \& Morgan, D. (1970). Determining sample size for research activities. Educational and Psychological Measurement, 30, 607-610.

Liu, X. \& Pange, J. (2015). Early childhood teachers' perceived barriers to ICT integration in teaching: a survey study in Mainland China. Comput. Educ.

2(1): $61-75$

Mevorach, M. (2017). Early Childhood Education Leadership. Tel-Aviv: Mofet Institute

Mynarikova, L., \& Novotny, L. (2020). Knowledge Society Failure? Barriers in the Use of ICTs and Further Teacher Education in the Czeck Republic. Sustainability, 20, https:// doi:10.3390/soc10040086

Noor, S., Isa, Md, F., \& Mazhar, F. F. (2020). Online Teaching Practices During the COVID-19 Pandemic. Educational Process: International Journal, 9(3), 169-184.

Yilmaz, A. B. (2019). Distance and face to face students' perceptions towards distance education: A comparative metaphorical study. Turkish Online Journal of Distance Education-TOJDE, 20(1), 1302-6488, https://files.eric.ed.gov/fulltext/EJ1201959.pdf.

Fernando, F., Patrizia, G. \& and Tiziana, G. (2020). Online Learning and Emergency Remote Teaching: Opportunities and Challenges in Emergency Situations. Societies, 10, 86; doi:10.3390/soc10040086 